\title{
Chiral Liquid Crystalline Electronic Systems
}

\author{
Masahiro Funahashi 1,2 (iD) \\ 1 Program for Advanced Materials Science, Faculty of Engineering and Design, Kagawa University, \\ 2217-20 Hayashi-cho, Takamatsu, Kagawa 761-0396, Japan; funahashi.masahiro@kagawa-u.ac.jp; \\ Tel.: +81-87-864-2411 \\ 2 Health Research Institute, National Institute of Advanced Industrial Science and Technology, \\ 2217-14 Hayashi-cho, Takamatsu, Kagawa 761-0395, Japan
}

check for

updates

Citation: Funahashi, M. Chiral Liquid Crystalline Electronic Systems. Symmetry 2021, 13, 672. https:// doi.org/10.3390/sym13040672

Academic Editor: Shoichi Ishihara and Sadahito UTO

Received: 22 March 2021

Accepted: 10 April 2021

Published: 13 April 2021

Publisher's Note: MDPI stays neutral with regard to jurisdictional claims in published maps and institutional affiliations.

Copyright: (C) 2021 by the author. Licensee MDPI, Basel, Switzerland. This article is an open access article distributed under the terms and conditions of the Creative Commons Attribution (CC BY) license (https:// creativecommons.org/licenses/by/ $4.0 /)$.

\begin{abstract}
Liquid crystals bearing extended $\pi$-conjugated units function as organic semiconductors and liquid crystalline semiconductors have been studied for their applications in light-emitting diodes, field-effect transistors, and solar cells. However, studies on electronic functionalities in chiral liquid crystal phases have been limited so far. Electronic charge carrier transport has been confirmed in chiral nematic and chiral smectic $C$ phases. In the chiral nematic phase, consisting of molecules bearing extended $\pi$-conjugated units, circularly polarized photoluminescence has been observed within the wavelength range of reflection band. Recently, circularly polarized electroluminescence has been confirmed from devices based on active layers of chiral conjugated polymers with twisted structures induced by the molecular chirality. The chiral smectic $C$ phase of oligothiophene derivatives is ferroelectric and indicates a bulk photovoltaic effect, which is driven by spontaneous polarization. This bulk photovoltaic effect has also been observed in achiral polar liquid crystal phases in which extended $\pi$-conjugated units are properly assembled. In this manuscript, optical and electronic functions of these chiral $\pi$-conjugated liquid crystalline semiconductors are reviewed.
\end{abstract}

Keywords: liquid crystal; liquid crystalline semiconductor; chiral nematic phase; chiral smectic C phase; ferroelectric liquid crystals; circularly polarized light; circularly polarized photoluminescence; circularly polarized electroluminescence; bulk photovoltaic effect; shift current

\section{Introduction}

\subsection{Chiral Liquid Crystalline Phases}

Molecular chirality often breaks the symmetry of liquid crystalline (LC) phases to induce twisted structures or electrical polarization. In the chiral nematic $\left(\mathrm{N}^{*}\right)$ phase, the nematic order is twisted along an axis perpendicular to the director, as shown in Figure 1a [1]. The helical structure of the $\mathrm{N}^{*}$ phase interacts with circularly polarized (CP) light. When the wavelength of the incident light coincides with the helical pitch of the $\mathrm{N}^{*}$ phase, the CP light with the same handedness of the $\mathrm{N}^{*}$ phase is reflected and that with the opposite handedness is transmitted through the $\mathrm{N}^{*}$ phase (Figure 1a). The wavelength reflected from the $\mathrm{N}^{*}$ phase, $\lambda$ is described in Equation (1), where $p, n$ and $\theta$ are helical pitch, refractive index, and incident angle, respectively.

$$
2\left(\frac{p}{2}\right) n \sin \theta=m \lambda
$$

The width of reflection band $\Delta \lambda$ is determined by the helical pitch and birefringence $\Delta n$, as expressed in Equation (2).

$$
\Delta \lambda=p \cdot \Delta n
$$

If fluorescent chromophores are doped in an $\mathrm{N}^{*}$ film with a left-handed helical structure, a right-handed CP fluorescence is emitted from the sample and a left-handed one is confined in the helical structure within the wavelength range of the reflection band of the $\mathrm{N}^{*}$ phase, as shown in Figure $1 \mathrm{~b}$. 
(a)

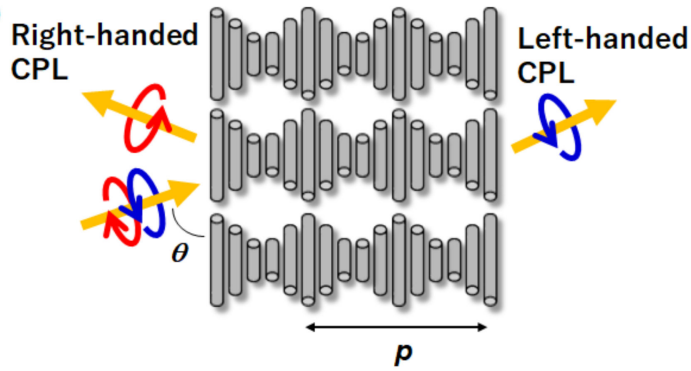

(b)

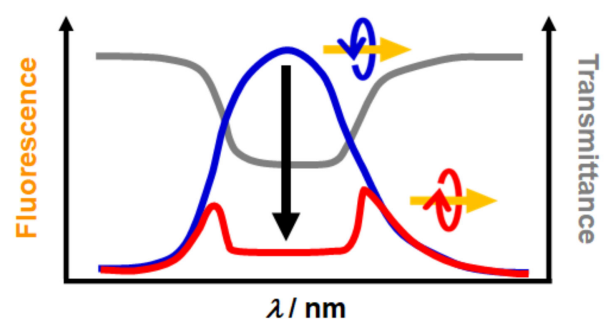

(c)

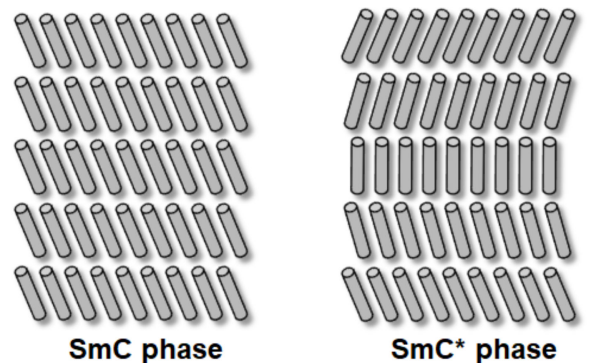

(d)

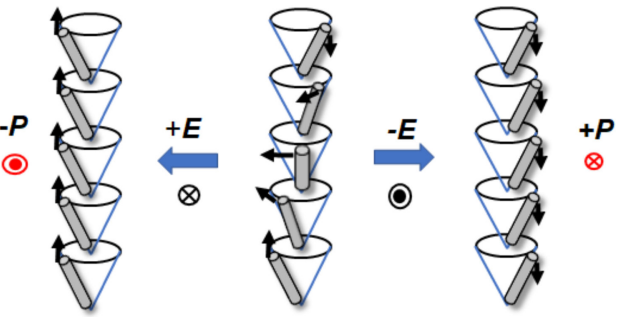

Figure 1. (a) Schematic illustration for supramolecular structures of a $\mathrm{N}^{*}$ phase and selective reflection. Red and blue arrows denote right- and left-handed CP light, respectively. (b) Relationship between a reflection band and CP PL spectra. (c) Schematic illustration for molecular aggregation structures of SmC and SmC* phases. Red and blue lines indicate rightand left-handed handed CP fluorescence spectra, respectively. Gray line denotes transmittance spectrum. (d) Schematic illustration for spontaneous polarization in an $\mathrm{SmC}^{*}$ phase.

In the smectic phase in which the director tilts from the layer normal, molecular chirality induces a twisted structure, as shown in Figure 1c. In a smectic C (SmC) phase consisting of achiral molecules, the director tilts from the layer normal and no positional order within a layer. In the chiral smectic $\mathrm{C}\left(\mathrm{SmC}^{*}\right)$ phase formed by chiral LC molecules, the director changes continuously along the layer normal so that the director draws a helix [2]. In the twisted state, an electrical polarization is canceled. As shown in Figure 1d, a DC voltage is applied in the direction perpendicular to the layer normal, the twisted structure is unwounded to induce macroscopic electrical polarization, which does not disappear after the removal of the $\mathrm{DC}$ bias. Therefore, the $\mathrm{SmC}^{*}$ phase is ferroelectric. Macroscopic electrical polarization can also be induced in the more ordered smectic phase by the tilted director from the layer normal and chirality.

Blue phases [3] and twisted-grain-boundary (TGB) phases [4] appear under strongly twisted conditions and formation of defects plays a significant role. Various unique optical and electro-optical phenomena have been studied, although these phases are electrically insulative and the author does not mention these phases in this review.

\subsection{Liquid Crystalline Semiconductors}

While conventional liquid crystals are electrical insulators, liquid crystals comprising extended $\pi$-conjugated units exhibit electronic charge carrier transport, which is observed in semiconductors [5-8]. Figure 2 shows molecular structures of typical LC semiconductors. Electronic charge carrier transport has been confirmed in columnar and calamitic LC systems. Electroactive $\pi$-conjugated moieties are self-organized in columnar or layer structures to form one or two-dimensional electronic systems. The electronic carrier transport in the smectic or columnar phases proceeds by a charge hopping mechanism considering energetic and positional disorders [9], although bandlike behavior was observed in ordered smectic and ordered columnar phases [10]. From the viewpoint of supramolecular chemistry, LC assemblies can be regarded as a field for integration of electronic functions of $\pi$-conjugated units [11]. 

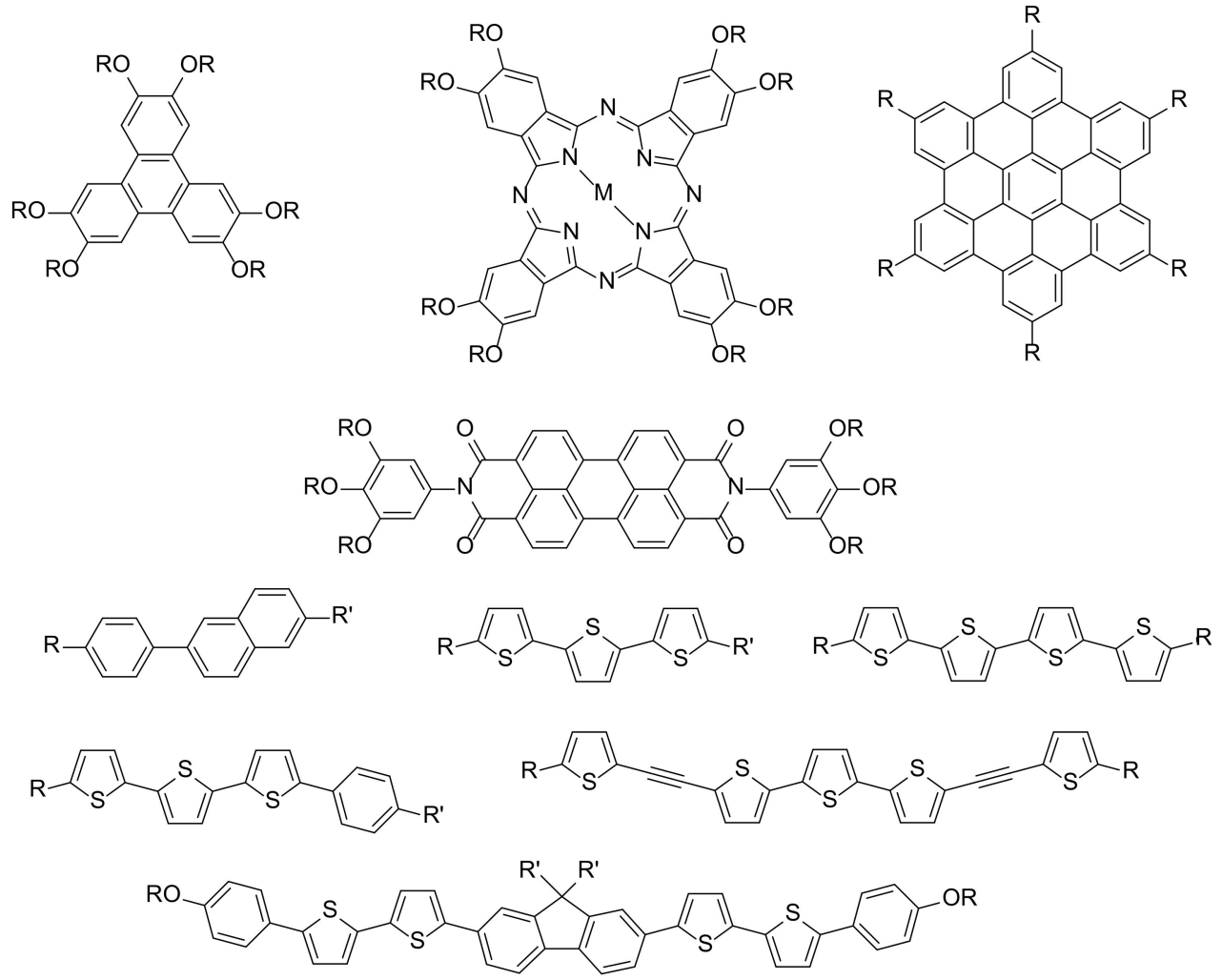

$\mathrm{R}, \mathrm{R}^{\prime}=$ alkyl

Figure 2. Molecular structures of typical liquid crystalline semiconductors.

As shown in Figure 2, triphenylene, hexabenzocoronene, phthalocyanine, perylene bisimide derivatives are known as columnar LC semiconductors [12-16]. Phenylnaphthalene and oligothiophene derivatives exhibit good carrier transport properties in smectic phases [17-21]. The application of LC semiconductors to electroluminescence device [6,22], field effect transistors [5,23-27], and solar cells have been investigated [28-30].

In the LC phases with a nematic order, ionic conduction had been predominant. However, electronic charge carrier transport has been confirmed in the nematic phases consisting of the rod-like and disk-like molecules comprising extended $\pi$-conjugated cores [31-34]. In chiral LC phases, electronic charge carrier transport should be possible if $\pi$-conjugated moieties aggregate closely, resulting in a large overlap between the $\pi$-conjugated units.

\subsection{Chiral Liquid Crystalline Electronic Systems}

Thus far, most of the studies on LC semiconductors have been limited to achiral systems. In liquid crystal phases, molecular chirality can induce supramolecular periodicity or electrically polarized structures, as mentioned in Section 1.1 Chiral liquid crystalline electronic systems can be constructed by assembling electroactive $\pi$-conjugated units in the chiral LC phase. The electronic function of the assemblies of the $\pi$-conjugated units is coupled with the supramolecular structures induced by molecular chirality to produce new optoelectronic properties. In this article, CP light emission in the chiral nematic phase and bulk photovoltaic effect in the ferroelectric phases of LC molecules comprising extended $\pi$-conjugated units are reviewed. Efficient $\mathrm{CP}$ light emitters are required for display and telecommunication applications. The bulk photovoltaic effect is driven by the internal electric field of ferroelectrics and has a potential to generate higher open-circuit voltages than the band gaps. These topics are related to new applications of electroactive liquid crystals beyond conventional display applications. 


\section{Electronic Systems with the Chiral Nematic Order}

The $\mathrm{N}^{*}$ phase indicates anisotropic transmission for $\mathrm{CP}$ light and can be used for $\mathrm{CP}$ light emitters. Conventional $\mathrm{N}^{*}$ liquid crystals are electrical insulators. $\mathrm{CP}$ light emission and lasing by optical pumping methods in dye-doped cholesteric liquid crystals have been studied using thick samples in the order of 10 to $100 \mu \mathrm{m}$ [35-38]. For the construction of electrical-pumping systems based on $\mathrm{N}^{*}$ liquid crystals, high density of $\pi$-conjugated chromophores is required for efficient electronic charge carrier transport. In this section, $\mathrm{CP}$ light emissions from $\mathrm{N}^{*}$ liquid crystals containing extended $\pi$-conjugated chromophores are reviewed.

\subsection{Circularly Polarized Photoluminescence from $N^{*}$ Liquid Crystals}

Chen et al. reported high quality CP photoluminescence (PL) from dye-doped $\mathrm{N}^{*}$ LCs, as shown in Figure 3a [39]. They used mixtures of achiral cyclohexane derivative 1 bearing three mesogens based on biphenylbenzoate and cyclohexane derivative 2 bearing a chiral mesogen. The mixture formed $\mathrm{N}^{*}$ glassy state and stable LC thin films were produced. An oligofluorene dye 3 was dissolved in the $\mathrm{N}^{*}$ matrices. Within the reflection band, CP PL was obtained with the $g_{\mathrm{e}}$ value of 1.8 in a $35 \mu \mathrm{m}$-thick film at the maximum. However, the width of the reflection band was only $60 \mathrm{~nm}$ and high $g_{\mathrm{e}}$ value was obtained in $20 \mathrm{~nm}$ (Figure 3b). As indicated in Equation (2), the band-width is proportional to the birefringence. This narrow region for the $\mathrm{CP}$ light emission was attributed to the small birefringence of the matrix LCs. The concentration of the $\pi$-conjugated chromophores was less than $1 \mathrm{~mol} \%$, and the LC glassy films were electrically insulative.

(a)

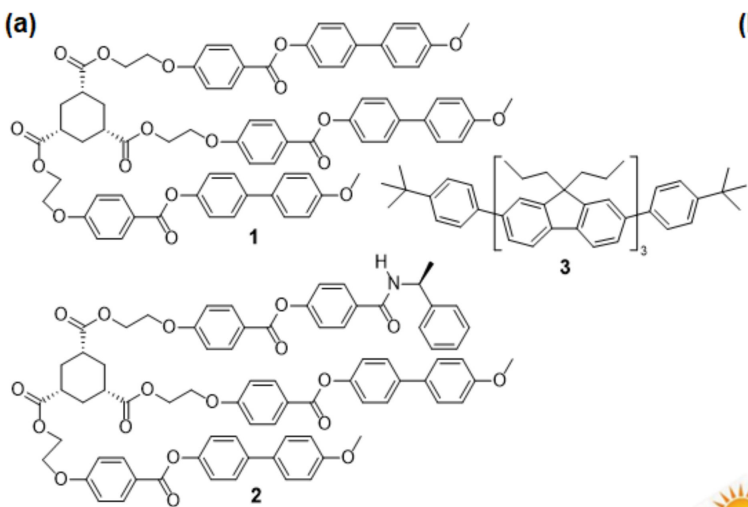

(b)

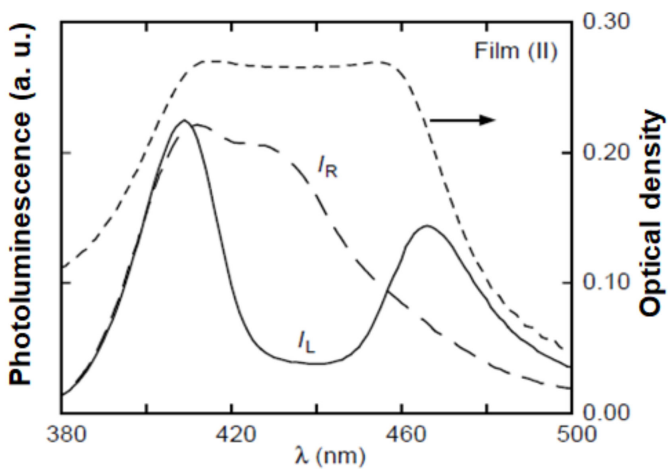

(c)

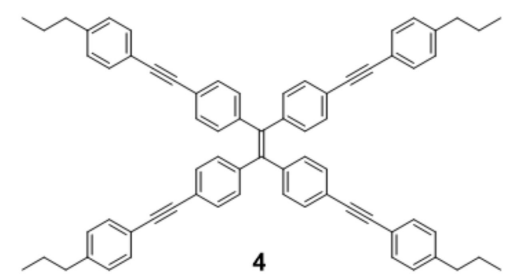

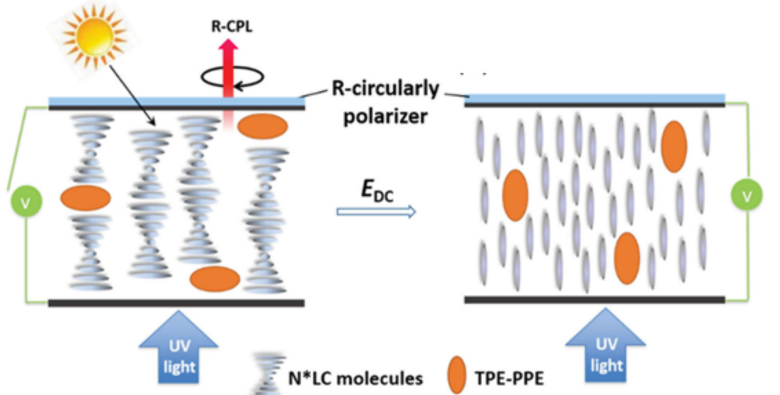

Figure 3. (a) Molecular structures of the components 1-3 of glassy $\mathrm{N}^{*}$ films emitting $\mathrm{CP}$ fluorescence. (b) $\mathrm{CP}$ fluorescence and absorption spectra from the glassy film. $I_{\mathrm{R}}$ and $I_{\mathrm{L}}$ denote the spectrum of right-handed left-handed $\mathrm{PL}$, respectively. The spectra were reproduced from Reference [39] with the permission from Springer and Nature. (c) CP light device using a $\mathrm{N}^{*}$ liquid crystal doped with a dye 4 exhibiting AIE activity. The images were reproduced from Reference [40] with the permission from John Wiley and Sons.

Zhao et al. demonstrated an LC display using $\mathrm{N}^{*}$ LC dissolving dye 4, which indicated aggregation-induced emission (AIE) (Figure 3b) [40]. The photoluminescence spectrum of the dye covered visible light $(400 \sim 600 \mathrm{~nm})$ and $\mathrm{CP}$ light emission was obtained in the region of the photonic band with the $g_{\mathrm{e}}$ value of 0.4 at best. The switching between non-polarized 
and CP light emission by the application of a DC voltage. They proposed a display that used reflection of sunlight in the daytime and emission from the dye excited by UV light at night.

The introduction of an extended $\pi$-conjugated unit is effective to increase the birefringence of the $\mathrm{N}^{*}$ liquid crystals as well as $\pi$-orbital overlap to promote electronic charge carrier transport. O'Neill and Kelly synthesized fluorene-based LC semiconductors $\mathbf{5}$ and 6 bearing chiral side chains, as shown in Figure 4a [41]. These materials formed glassy $\mathrm{N}^{*}$ film at room temperature and $\pi$-conjugated units aggregated in the glassy $\mathrm{N}^{*}$ phase with high intensity. These molecules had an extended $\pi$-conjugated unit and high hole mobility exceeding $10^{-4} \mathrm{~cm}^{2} \mathrm{~V}^{-1} \mathrm{~s}^{-1}$ at room temperature. Moreover, the long $\pi$-conjugated system resulted in high birefringence and the width of the reflection band exceeded $300 \mathrm{~nm}$ covering a wide region of visible light. The $g_{\mathrm{e}}$ value of CP PL exceeded 1.5 from 457 to $561 \mathrm{~nm}$ in a sample with a thickness of $3 \mu \mathrm{m}$. The reflection band can be tuned by mixing compound 5 with compound 6 .

(a)

(b)
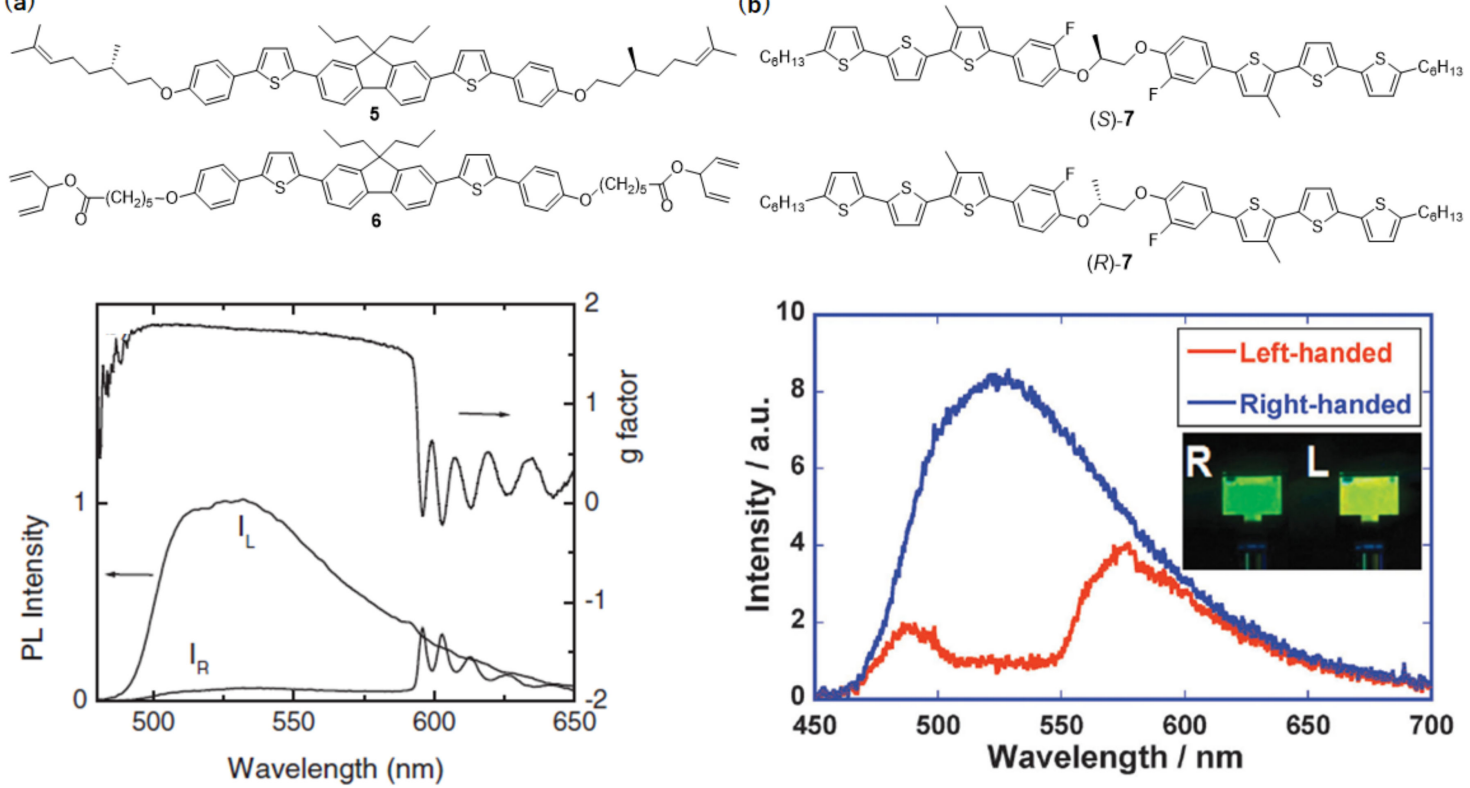

Figure 4. CP fluorescence from non-diluted $\pi$-conjugated $N^{*}$ liquid crystals. (a) Fluorene derivatives, CP PL spectra, and $g$ factor as a function of wavelength. The spectra were reproduced from [41] with the permission from John Wiley and Sons. (b) Phenylterthiophene derivatives and CP PL spectra. The inset is a photograph of the LC cell emitting CP light through a $\mathrm{CP}$ filter. The spectra were reproduced from Reference [42] with the permission from the Royal Society of Chemistry.

Hamamoto and Funahashi synthesized dimeric $\mathrm{N}^{*} \mathrm{LC}$ based on phenylterthiophene skeleton (Figure 4b) [42]. Due to the small volume of the side chain and chiral moieties, the density of the $\pi$-conjugated chromophores was increased further. The LC 7 exhibited an $\mathrm{N}^{*}$ phase at room temperature and ambipolar electronic charge carrier transport. Due to the extended $\pi$-conjugated system, the width of the reflection band was $100 \mathrm{~nm}$. Within the reflection band, the $g_{\mathrm{e}}$ value of the CP PL reached 1.5 in a cell with a thickness of $9 \mu \mathrm{m}$. Reflection band could be red-shifted by mixing (R)- and (S)-7. The $\mathrm{N}^{*}$ phase of LC 7 was fluidic at an elevated temperature and the switching between the $\mathrm{CP}$ and non-polarized states by the application of an electric field.

\subsection{Circularly Polarized Electroluminescence from Twisted Electronic Systems}

CP EL has been confirmed in the devices with light-emitting layers, including chiral rare-earth metal complexes, chiral conjugated polymers, and chiral low-molecular-weight dyes. In the cases of chiral metal complexes and low-molecular weight-dyes, the $g_{e}$ values of electroluminescence were in the order of $10^{-3}$ to $10^{-2}$. Exceptionally, chiral Pt complex 
works as effective CP light emitters in a few EL devices, indicating the $g_{\mathrm{e}}$ value of 0.3 at most. Chiral low molecular weight dye exhibiting thermally activated delayed fluorescence has also been designed, but the $g_{\mathrm{e}}$ values are less than 0.1 at the present stage [43-46].

Conjugated polymers bearing chiral alkyl chains form twisted aggregates by solution processes. A few polymers exhibit the $\mathrm{N}^{*}$ order in the thin film states. This helical structure of $\pi$-conjugated aggregates enhances circularly polarization of the PL and EL.

The first CP EL device was reported by Meijer and coworkers in 1997 [47], as shown in Figure 5a. They synthesized poly( $p$-phenylenevinylene) derivative 8 bearing chiral alkyl chains and fabricated EL devices, including light-emitting layer of the conjugated polymers with a thickness of $300 \mathrm{~nm}$ by a spin-coating method. The $g_{\mathrm{e}}$ value was $1.7 \times 10^{-3}$ at $600 \mathrm{~nm}$. They improved the $g_{\mathrm{e}}$ value to $0.35 \mathrm{in}$ an EL device with a thickness of $70 \mathrm{~nm}$ using a nonafluorene derivative bearing chiral alkyl chains [48].

(a)
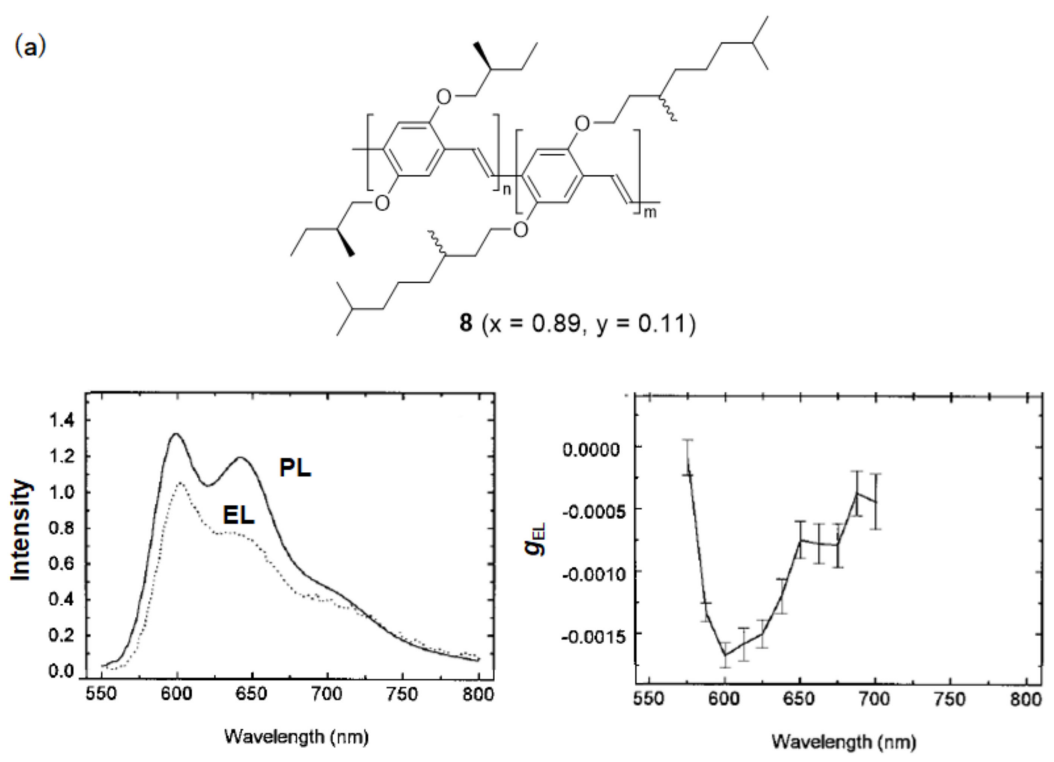

(b)
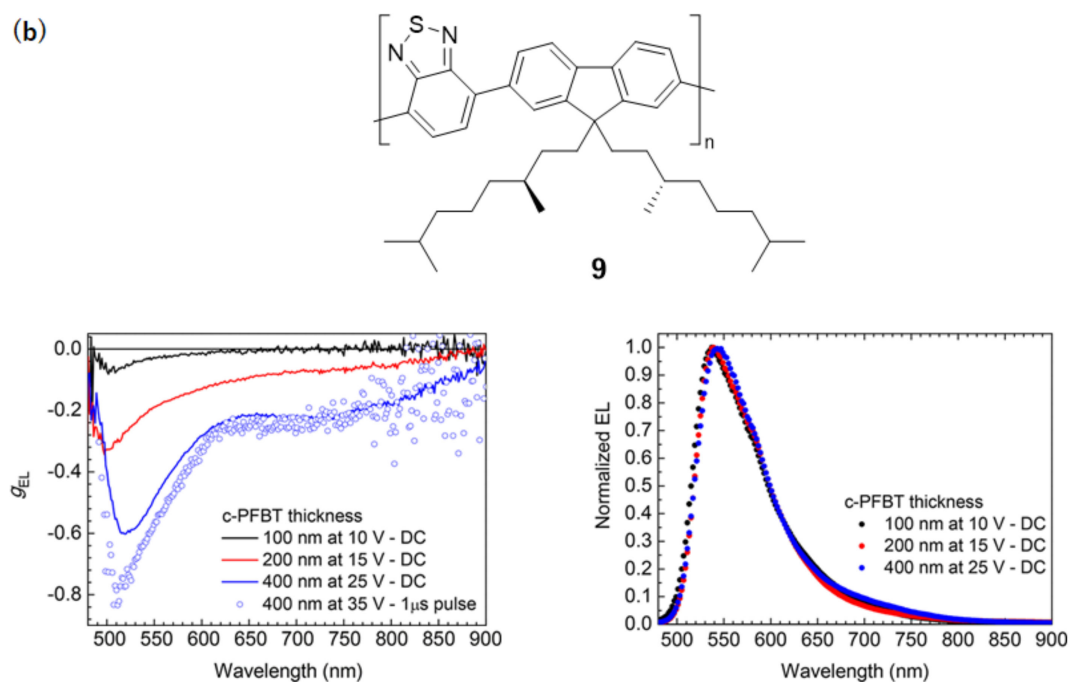

Figure 5. (a) Chiral poly(p-phenylenevinylene) derivative as well as EL and PL spectra. The $g_{\mathrm{e}}$ value for EL as a function of the wavelength is also indicated. The spectra were reproduced from [47] with the permission from the American Chemical Society. (b) Chiral polyfluorene and the $g_{\mathrm{e}}$ value of the EL from samples with various thicknesses as a function of the wavelength. EL spectra from samples with various thicknesses are also indicated. The graphs were reproduced from Reference [49] with the permission from the American Chemical Society (https:/ / pubs.acs.org/doi/10.1021/acsnano. $7 b 07390$ accessed on 1 January 2021). 
In 2017, Nuzzo and coworkers reported CP EL using a poly(fluorene-co-benzothiadiazole) derivative 9 bearing chiral alkyl side chains [49], as shown in Figure 5b. The $g_{e}$ value increased with the increase in the thickness of the light emitting layer, to be 0.8 at $500 \mathrm{~nm}$ with the thickness of $400 \mathrm{~nm}$ under pulse DC bias application. This result indicated that the generation of CP light was related to the helical structure of the conjugated polymer layer and relatively thick light emitting layer should be required for a high $g_{\mathrm{e}}$ value.

CP EL was observed from the devices with light emitting layers using achiral conjugated polymer 10 doped with chiral inactive compound 11, as shown in Figure 6a. The CP EL devices with the $g_{\mathrm{e}}$ value approaching 1 and the luminance in the order of $10^{3} \mathrm{cdm}^{-2}$ were fabricated [50]. The $g_{\mathrm{e}}$ value of EL is higher than that of PL and depended on the film thickness and twist angle of the conjugated polymer orientation. As shown in Figure 6b, light was emitted from the whole area of the sample in PL, while light was emitted from a specific area in EL. Additionally, the $g_{\mathrm{e}}$ value of EL changed depending on the distance between the emission zone and the cathode, indicating the influence of the reflection of the CPL at the cathode on the $g_{e}$ value $[51,52]$. In order to obtain high quality CP EL, reflection from the cathode, as well as twisted angle of the conjugated polymer aggregation, should be considered in the CP EL device design.

(a)
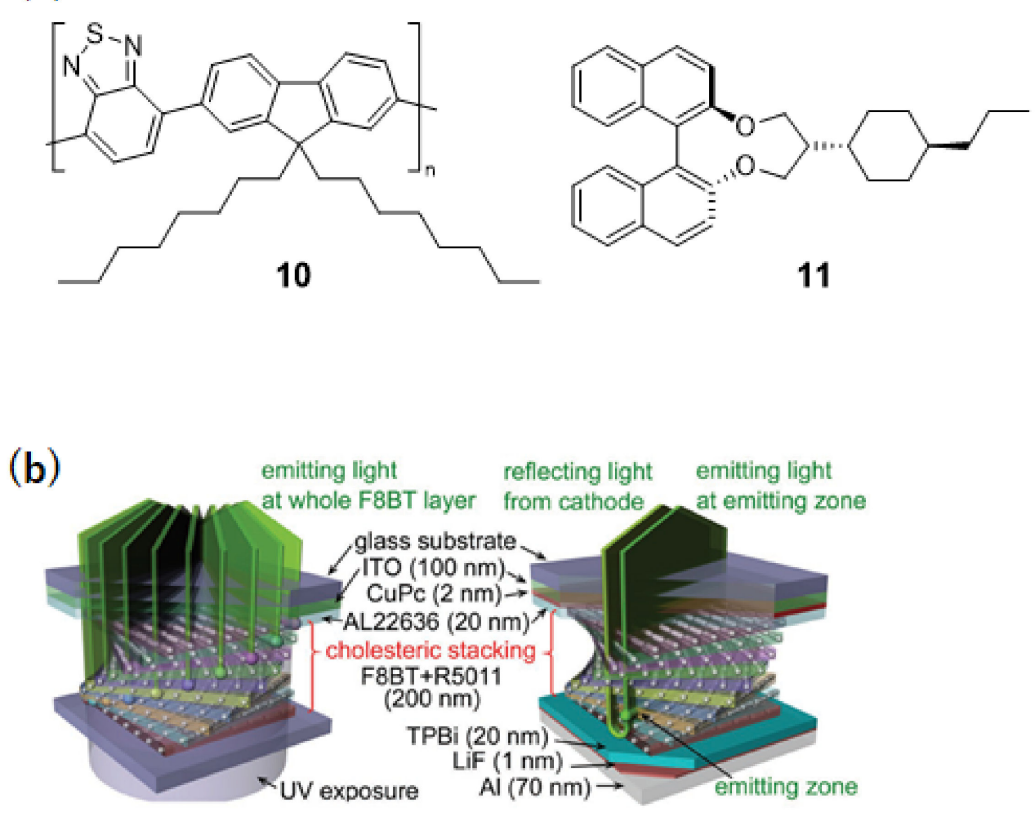

Figure 6. (a) Molecular structures of conjugated polymer $\mathbf{1 0}$ and chiral dopant $\mathbf{1 1}$ for CP EL devices. (b) Schematic illustration for CP PL (left) and CP EL (right) affected by the twist angle of the conjugated polymers, the position of light emission zone and reflection from the cathode. The image was reproduced from Reference [51] with the permission from John Wiley and Sons.

\section{Liquid Crystalline Electronic Systems with Ferroelectricity}

Conventional ferroelectrics have large bandgaps, resulting in their low charge carrier densities. Therefore, they are electrically insulative. However, electrical conductivity can be induced if electronic charge carriers are injected into the ferroelectrics. In such a situation, the electronic charge carrier transport can be coupled with the electrical polarization originating from the ferroelectricity. The bulk photovoltaic effect observed in lithium niobate and bismuth ferrite is attributed to the coupling between the transport of photogenerated charge carriers and the internal electric field produced by the spontaneous polarization [53]. 


\subsection{Bulk Photovoltaic Effect in Ferroelectric Solids}

Figure 7a shows a schematic illustration of a photovoltaic effect based on a p-n junction. The conventional photovoltaic effect is driven by local electric fields formed at junctions between $\mathrm{p}$ - and n-type semiconductors in a case of a p-n junction, or a metal and a semiconductor in a case of a Schottky junction. The built-in potential is determined by the difference between chemical potentials of semiconductors and metals [54]. Therefore, a built-in potential does not exceed a bandgap of a semiconductor. Open-circuit voltages of solar cells based on inorganic and organic solar cells are typically around $1 \mathrm{~V}$ [55]. For solar cells based on the p-n junction, series connection of solar cells is required for generation of a high voltage larger than the bandgap. Tandem structures of photovoltaic components using different active materials are also studied for the increase in the open circuit voltages and conversion efficiencies of inorganic and organic solar cells [56,57].

In contrast to the conventional photovoltaic effect, a larger open-circuit voltage can be generated in an anomalous or bulk photovoltaic effect because the driving force of the photovoltaic effect is a strong electric field formed in the bulk of the materials because the open circuit voltage is proportionate to the electric polarization of the material, as shown in Figure $7 \mathrm{~b}$ [53]. Crystalline films of lithium niobate and barium titanate exhibit the bulk photovoltaic effect in which the open circuit voltages exceed their bandgaps [58,59]. However, the photocurrents were very low, resulting in low power conversion efficiency because of their large bandgaps and low conductivities. Recently, the bulk photovoltaic effect in bismuth ferrite has been studied. Bismuth ferrite exhibits a ferroelectric phase at room temperature and has absorption edge around $560 \mathrm{~nm}$. Choi et al. observed the inversion of the polarity of rectification and photocurrent by the change of poling bias polarity [60]. The significance of polarization boundaries is recognized for the generation of high open-circuit voltages in the bulk photovoltaic effect, as shown in Figure 7c [61].

For organic electronic materials, the examples of the bulk photovoltaic effect have been quite limited. First of all, the variety of organic ferroelectrics is limited compared to inorganic materials [62]. A classical example is single crystals of tartaric acid salts. Crystals in which hydrogen-bonding networks are formed, such as croconic acid, are extensively studied [63]. Poly(vinylidene fluoride) films are typical ferroelectric polymers and applications to sensors and memories are investigated [64]. Ferroelectric liquid crystals are studied for display applications [65]. Above-mentioned organic ferroelectric materials bear no or small $\pi$-conjugated systems and fundamentally electrical insulators. In these materials, photovoltaic effect could not be expected because of low electrical conductivity and no absorption in UV-visible light region. For this purpose, extended $\pi$-conjugated systems, which absorb UV-visible light and contribute to electronic charge carrier transport, should be built in the polar molecules.

Among organic systems, the first case of bulk photovoltaic effect was observed in films of dye-doped poly(vinylidene fluoride) 12 (Figure 8a) by Sasabe and coworkers [66]. Poly(vinylidene fluoride) is a typical ferroelectric polymer exhibiting high spontaneous polarization around $5 \mu \mathrm{Ccm}^{-2}$ in the $\beta$-form. However, it is an electrical insulator and has no absorption bands in the visible and near UV region. Therefore, acridine orange absorbing visible light was doped in the polymer films. In the poled films, photocurrent response and pyroelectric effect were observed under open-circuit conditions, as shown in Figure 8a. A high open-circuit voltage in the order of $10^{4}$ was obtained, but the photocurrent was too small, resulting in a low conversion efficiency of $0.25 \%$. Moreover, the dye molecules worked as carrier traps to decrease the photocurrent.

Tasaka and coworkers reported a bulk photovoltaic effect of which polarity could be inverted by poling DC bias applications in a polycrystalline thin film of triphenylene hexacarboxylic ester [67]. Figure 8b shows a molecular structure of the ferroelectric triphenylene derivative and the photocurrent response in the thin film state. In crystalline thin films of 2,3,6,7,10,11-hexakis(4-octyloxybenzoyloxy)triphenylene 13, a macroscopic electric polarization is induced by the orientation of dipole moments of the six carbonyl groups connecting to a triphenylene core, as shown in Figure 8b. A hole transport proceeded through 
$\pi$-stacks consisting of triphenylene units. In the crystal phase of this compound, the spontaneous polarization was $200 \mathrm{nCcm}^{-2}$. When a UV light of the intensity of $10 \mathrm{mWcm}^{-2}$ was illuminated, the photocurrent density reached $5 \mathrm{nAcm}^{-2}$, as shown in Figure 8b. The power conversion efficiency was $0.5 \%$ and the internal electric field should be deduced to be $1.4 \mathrm{MVcm}^{-1}$. This material has $\pi$-stacking structures, which is favorable for an efficient electronic charge carrier transport. However, the carrier generation efficiency should not be sufficiently high, resulting in low conversion efficiency.

Nakamura and coworkers confirmed a shift current in ferroelectric charge transfer complex of tetrathiafulvalene $\mathbf{1 4}$ and chloranil 15, which formed a non-centrosymmetric crystalline structure (Figure 9) [68]. In the single crystals, ferroelectricity was derived from charge transfer between the electron-acceptor and donor. The spontaneous polarization exceeded $5 \mathrm{mCcm}^{-2}$ below $70 \mathrm{~K}$. By visible light illumination, directional photocurrent was observed and the polarity could be inverted by the change in the polarity of the poling DC bias. However, the crystals exhibited a ferroelectric phase only below $80 \mathrm{~K}$ and consequently this bulk photovoltaic effect disappeared at room temperature.

(a)

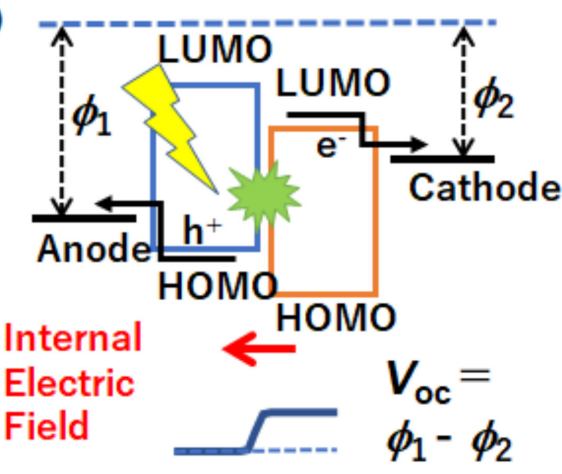

Photovoltaic effect based on p-n junction

(c)

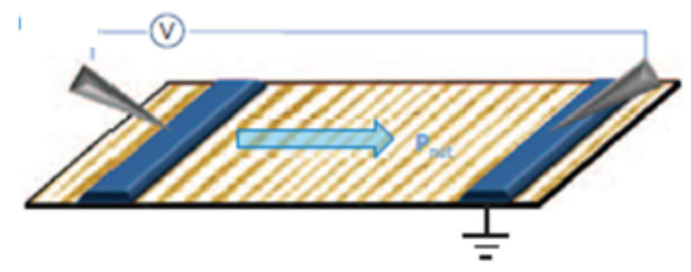

(b)

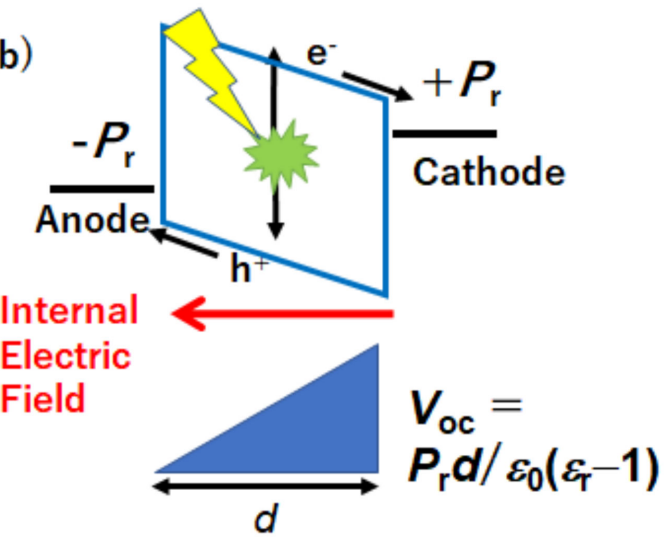

Bulk photovoltaic effect based on ferroelectricity

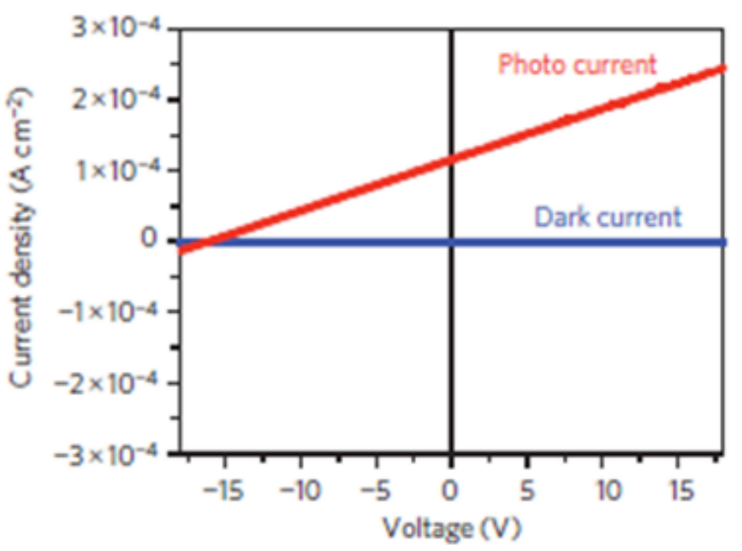

Figure 7. Schematic illustrations for (a) a conventional photovoltaic effect based on a p-n junction. The parameters, $V_{\mathrm{oc}}$ $\phi_{1}, \phi_{2}, P_{\mathrm{r}}, \varepsilon_{0}, \varepsilon_{\mathrm{r}}$, and $d$ denote open circuit voltage, work functions of anode and cathode, residual polarization, dielectric constants of vacuum, relative permittivity of the sample, and sample thickness, respectively. (b) a bulk photovoltaic effect in a ferroelectric. (c) An example of the bulk photovoltaic effect in bismuth ferrite. A schematic illustration for a measurement of the planar sample containing polarization boundaries and the current-voltage characteristics. The image and graph were reproduced from reference [61] with the permission from Springer Nature. 
(a)<smiles></smiles>

12
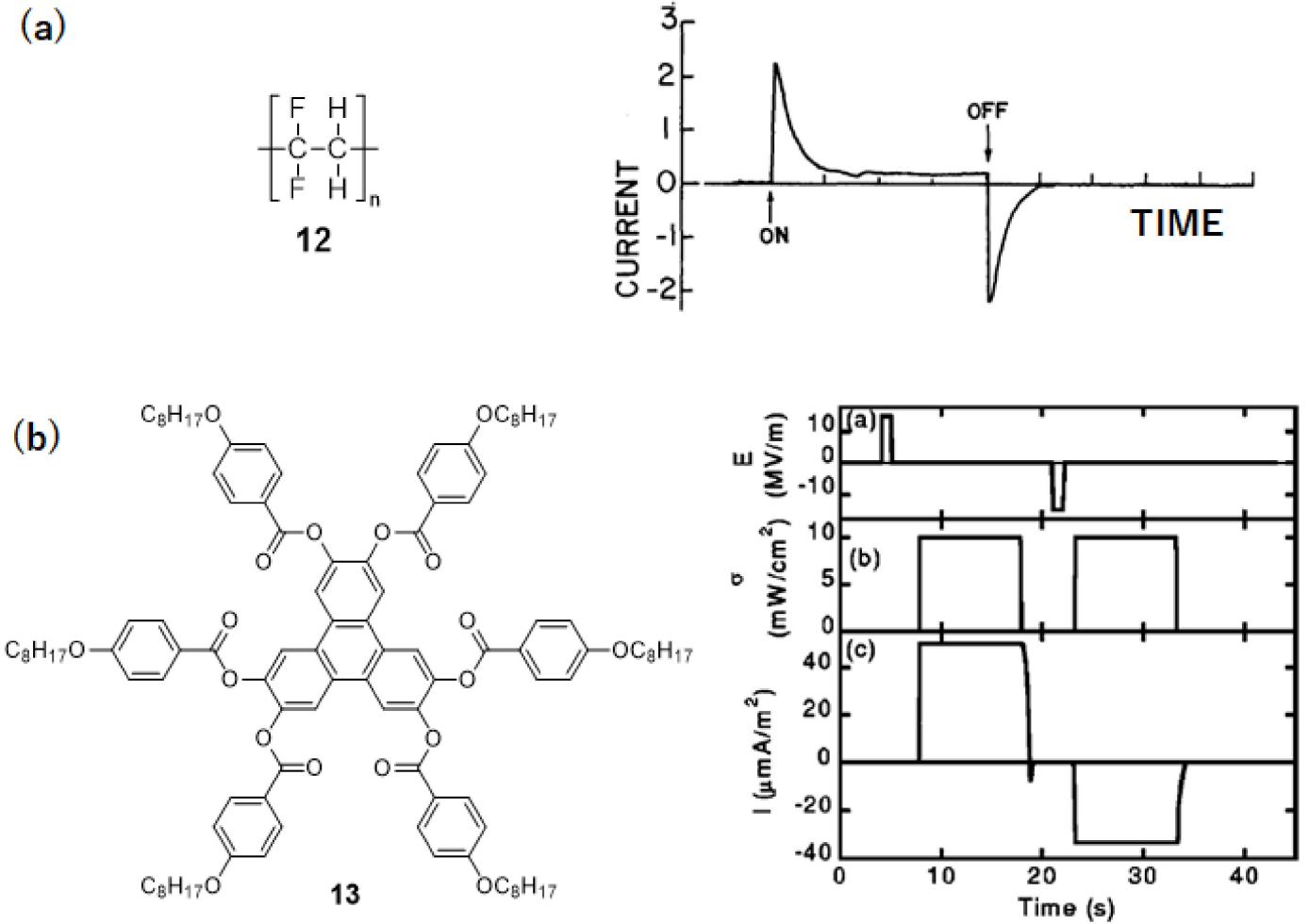

Figure 8. (a) Molecular structure of poly(vinylidene fluoride) $\mathbf{1 2}$ and the photocurrent response of the poled thin film under a short-circuit condition. The graph was reproduced from Reference [66] with the permission from Springer Nature. (b) Molecular structure of 2,3,6,7,10,11-hexakis(4-octyloxybenzoyloxy)triphenylene 13 and the photocurrent response under a short-circuit condition. The graph was reproduced from Reference [67] with the permission from the American Physical Society.

(a)<smiles>C1=CSC(=C2SCCS2)S1</smiles>
14<smiles>O=C1C(Cl)=C(Cl)C(=O)C(Cl)=C1Cl</smiles>

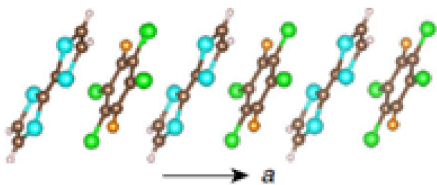

(b)

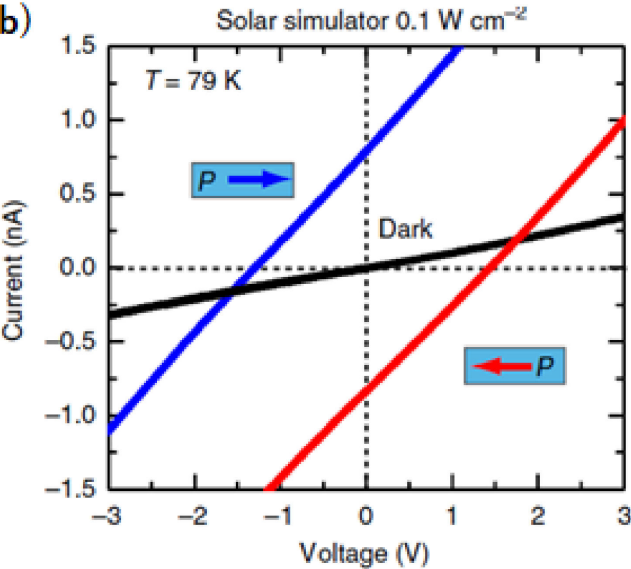

Figure 9. (a) Molecular structures of a charge transfer complex between tetrathiafulvalene 14 and chloranil 15 and the crystal structure of the charge transfer complex. (b) Current-voltage characteristics of the charge transfer complex at $79 \mathrm{~K}$. The image and graph were reproduced from Reference [68] with the permission from Springer Nature.

\subsection{Bulk Photovoltaic Effect in Liquid Crystalline Systems}

\subsubsection{Ferroelectric Liquid Crystals}

Figure 10 shows molecular structures of typical Ferroelectric liquid crystals (FLCs). FLCs were discovered by Meier and coworkers in 1975 [69] and applied to display devices by Clark and Lagerwall in 1980 [70]. The first type of FLC molecules consisted of a rod-like 
rigid core and a chiral alkyl chain, which broke a centrosymmetry of the mesomorphic system. The first example of FLC is compound 16. The FLC phases have a layer structure in which the molecules are tilted to the layer normal. The typical FLC phase is a chiral smectic $\mathrm{C}\left(\mathrm{SmC}^{*}\right)$ phase, as shown in Figure $1 \mathrm{~b}$.
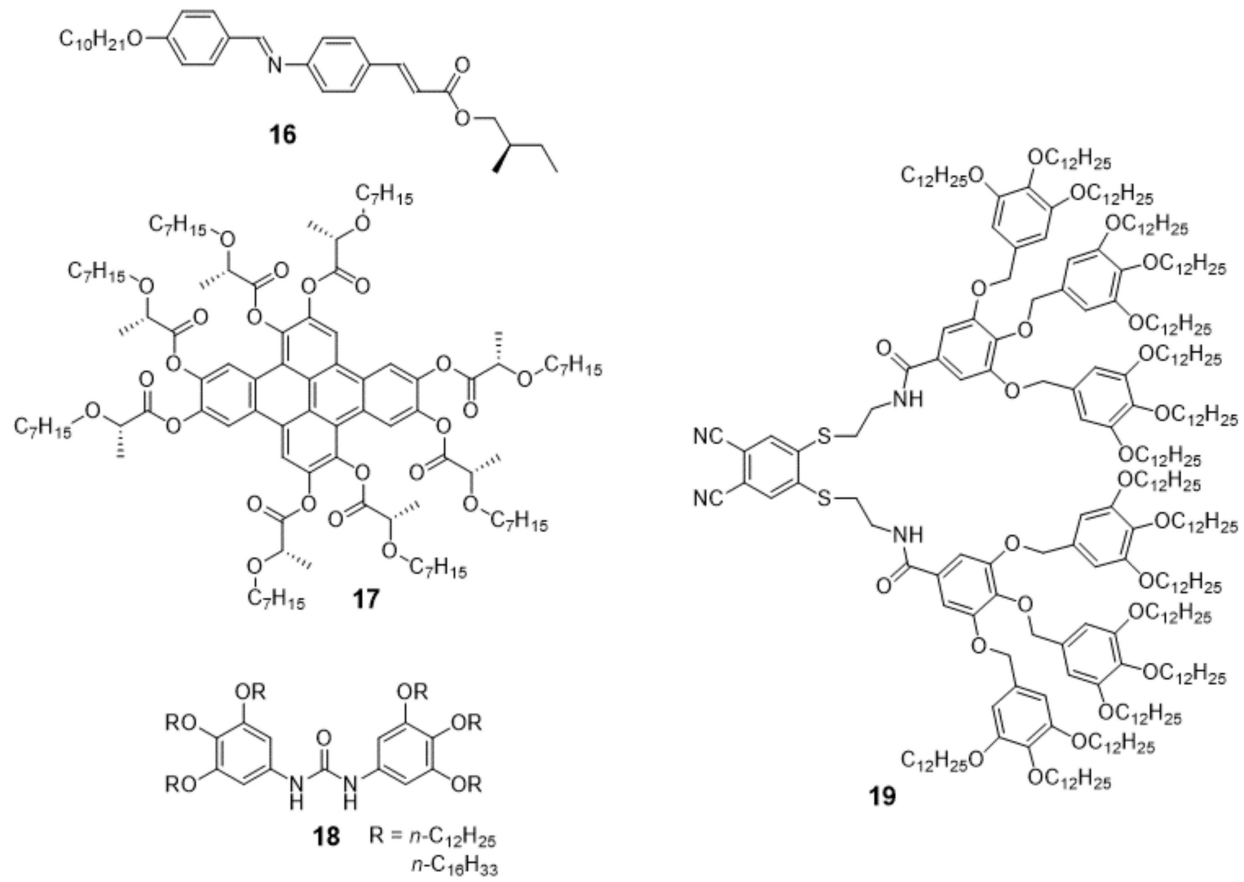

Figure 10. Molecular structures of ferroelectric liquid crystals.

The second type of the FLC phase is columnar phases. Bock and Helfrich synthesized and dibenzopyrene derivative $\mathbf{1 7}$ bearing chiral alkyl chains to exhibit ferroelectricity [71]. As observed in the $\mathrm{SmC}^{*}$ phase, non-centrosymmetry induced by tilted normals of the $\pi$-conjugated disks to the columnar axes as well as molecular chirality was the origin of the ferroelectricity. The spontaneous polarization was induced perpendicular to the columnar axes. In contrast, Kishikawa and coworkers synthesized achiral diphenyl urea derivatives 18 bearing long alkyl chains, which formed a polar columnar phase in 2005 [72]. In the columnar phase, the origin of the electrical polarization was one-dimensional hydrogenbonding series to generate the polarization parallel to the columnar axes. Polarization inversion was caused by the exchange of the hydrogen bonding between urea molecules.

In 2012, Miyajima et al. achieved the construction of ferroelectric columnar phase by an approach from supramolecular chemistry [73]. They synthesized achiral phthalonitrile derivative 19 bearing amide moieties and alkyl side chains. Four molecules of compound 19 form an umbrella-like aggregate via hydrogen bonding between amide moieties and they stack in a one-dimensional manner to form columnar aggregates. The cyano groups of phthalonitrile units generated a macroscopic electrical polarization parallel to the columnar axes. They confirmed the ferroelectricity by a polarization inversion current technique and second harmonic generation (SHG) measurement.

In the abovementioned studies, the LC molecules did not comprise extended $\pi$ conjugated systems and the FLC phases were electrically insulative. For the coupling of the ferroelectricity with electronic functions, extended $\pi$-conjugated units and polar moieties should be integrated in the molecules and they should be organized properly in the supramolecular structures.

\subsubsection{Chiral LC Systems}

Funahashi and coworkers have paid attention to chiral supramolecular systems. They synthesized FLCs based on a phenylterthiophene skeleton [74]. A chiral alkyl chain 
and a fluorophenyl unit were connected to a terthiophene core, which exhibited good carrier transport characteristics in smectic phases. Phenylterthiophene derivatives 20-22 (Figure 11a) exhibited a SmC $\mathrm{C}^{*}$ and $\mathrm{SmG}^{*}$ phases and the hole mobilities were in the order of $10^{-4} \mathrm{~cm}^{2} \mathrm{~V}^{-1} \mathrm{~s}^{-1}$ in the $S m C^{*}$ phase and $10^{-2} \mathrm{~cm}^{2} \mathrm{~V}^{-1} \mathrm{~s}^{-1}$ in the $S \mathrm{SG}^{*}$ phase. The spontaneous polarization reached $100 \mathrm{nCcm}^{-2}$ in the $\mathrm{SmC}^{*}$ phase.

(a)
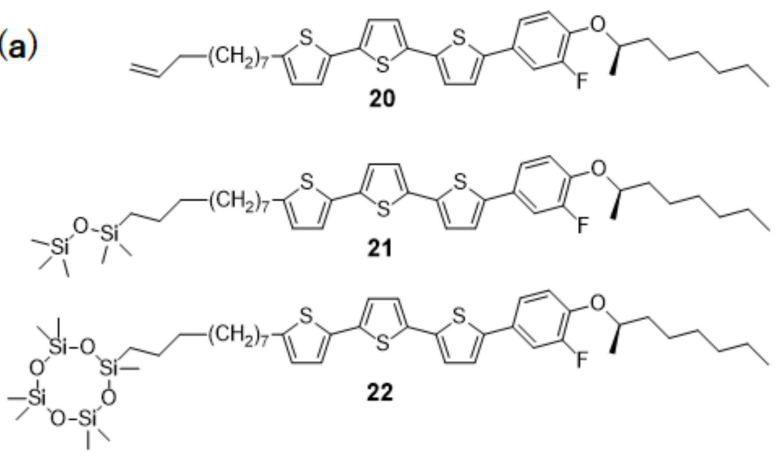

(b)

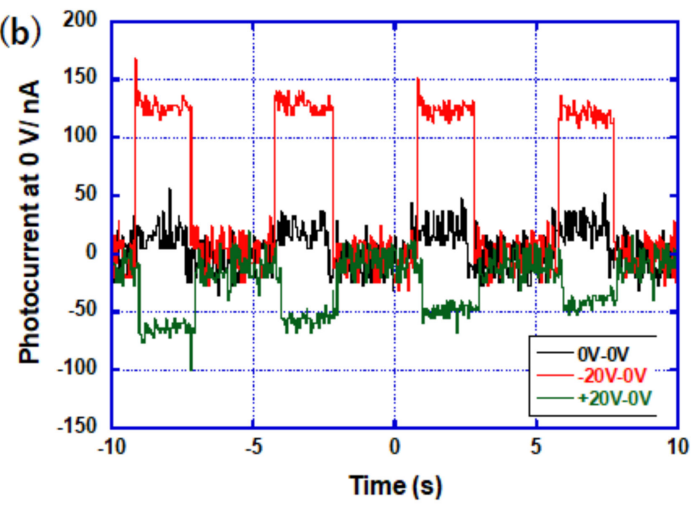

Figure 11. (a) Molecular structure of ferroelectric LC semiconductors 20-22. (b) Photocurrent response in the $\mathrm{SmC}^{*}$ phase of compound 20 for UV light illumination under a short circuit condition. Black, red, and green lines denote a non-polarized state, polarized state with the illuminated electrode charged positively, and polarized state with that charged negatively, respectively. The graph was reproduced from Reference [74] with the permission from the Royal Society of Chemistry.

Figure $11 \mathrm{~b}$ shows photocurrent response for UV light illumination in the $\mathrm{SmC}^{*}$ phase of compound $\mathbf{2 0}$ under a short circuit condition. For UV light illumination, a photocurrent was induced under the zero bias after the application of a poling DC bias. The polarity of the photocurrent was contrary to that of the poling bias and it was inversed by the change in the polarity of the poling bias. The same photovoltaic behaviors were observed in the $\mathrm{SmC}^{*}$ phase of the other phenylterthiophene derivatives and the photocurrent response was proportional to the spontaneous polarization in the $\mathrm{SmC}^{*}$ phase [75].

The photovoltaic response of which polarization is contrary to the poling bias prior to light illumination can be induced by an electrical polarization of ionic impurities. The origin of the photovoltaic effect was confirmed by the comparison of photovoltaic behaviors between the FLC samples with various enantiomer purities [76]. As shown in Figure 12a, the photocurrent in the $\mathrm{SmC}^{*}$ phase of compound $\mathbf{2 0}$ increased with an increase in the enantiomer purity. The photovoltaic effect disappeared in the racemic mixture. This result indicates that the photovoltaic effect should be attributed to the symmetry breaking by molecular chirality in the $\mathrm{SmC}^{*}$ phase, but not to contamination of ions.

These phenylterthiophene-based FLCs exhibit chiral ordered smectic phases below the $\mathrm{SmC}^{*}$ phase. If a sandwich type sample of the FLCs is cooled from the $\mathrm{SmC}^{*}$ phase to the ordered smectic phase under the DC bias application, the macroscopic electric polarization in the $\mathrm{SmC}^{*}$ phase is immobilized in the ordered smectic phase. The increase of the carrier mobility in the ordered smectic phase compared to that in the SmC* phase results in the enhancement of the photovoltaic effect in the ordered smectic phase, as shown in Figure 12b [77].

Funahashi and coworkers synthesized a double chiral FLC 23 based on bisfluorophenylterthiophene bearing lactic ester moieties, as shown in Figure 13a [78]. This compound exhibited a chiral smectic A $\left(\mathrm{SmA}^{*}\right)$ phase below which an ordered smectic phase appeared. When a thin film sample was cooled from the $S m A^{*}$ phase to the ordered smectic phase under the application of a DC bias, the macroscopic electrical polarization was induced in the ordered smectic phase. Figure $13 \mathrm{~b}$ shows a current-voltage characteristic for UV light illumination in the polarized state of the chiral ordered smectic phase of compound 23. Due to the internal electric field produced by the macroscopic polarization, the bulk photovoltaic effect was confirmed in the ordered smectic phase of this compound 
with an open-circuit voltage of $0.8 \mathrm{~V}$. Moreover, the electrical polarization in the ordered smectic phase lowered the injection barrier from the cathode and anode to the FLC layer, resulting in electroluminescence. From uniaxially aligned samples, linearly polarized electroluminescence was obtained and the polarized plane of the electroluminescence was rotated by 90 degrees. by the inversion of the poling bias polarity in the cooling process from the SmA* phase to the ordered smectic phase, as shown in Figure 13c.

(a)

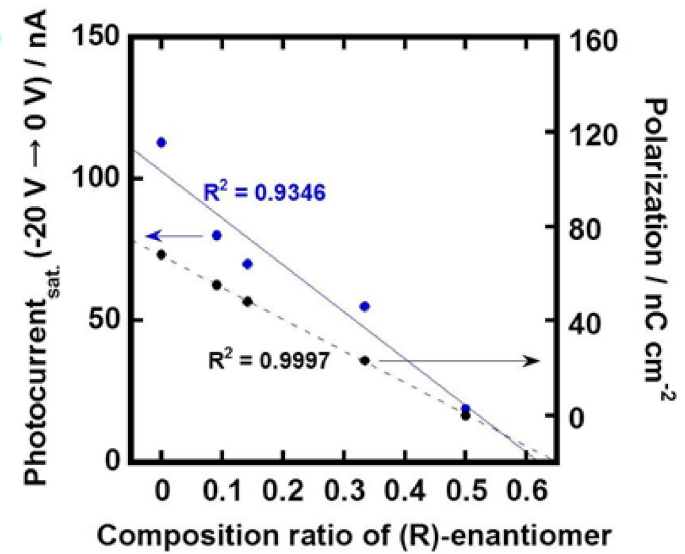

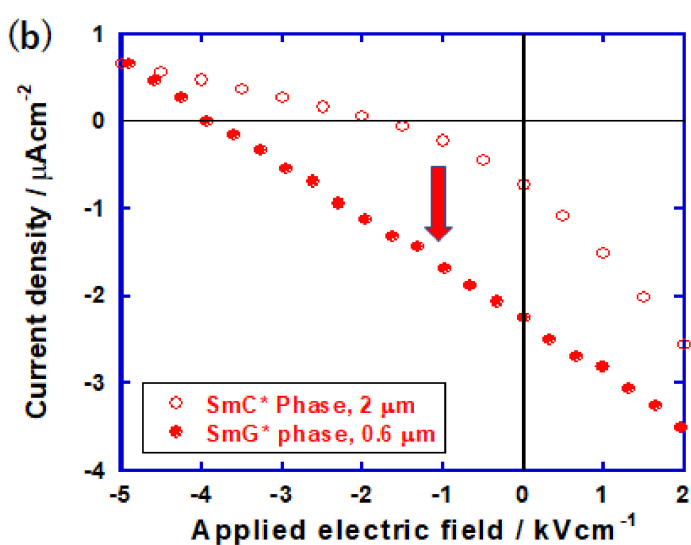

Figure 12. (a) Photocurrent under a short circuit condition in the $\mathrm{SmC}^{*}$ phase of compound 20 as a function of the enantiomer purity. The graph was reproduced from Reference [76] with permission from the PCCP Owner Societies. (b) Current-voltage characteristics in the $\mathrm{SmC}^{*}$ and $\mathrm{SmG}^{*}$ phases of compound 20. The graph was reproduced from Reference [77] with the permission from Elsevier.

(a)

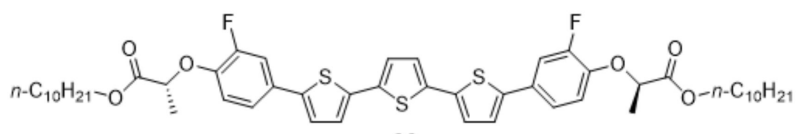

(b)

23

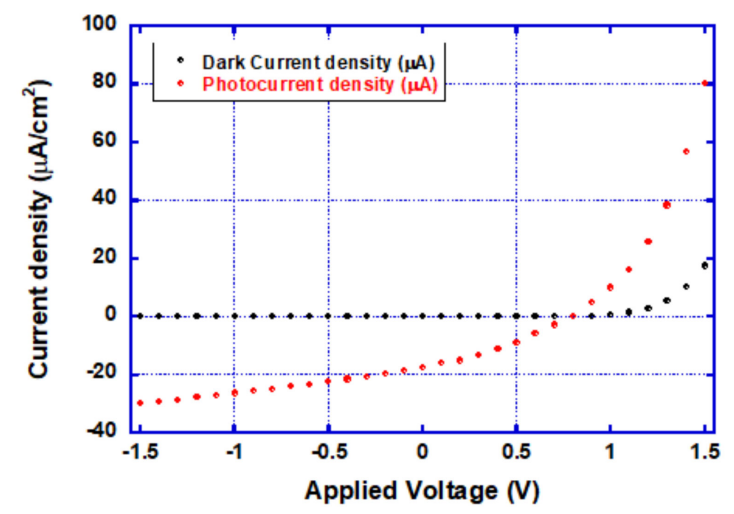

(c)
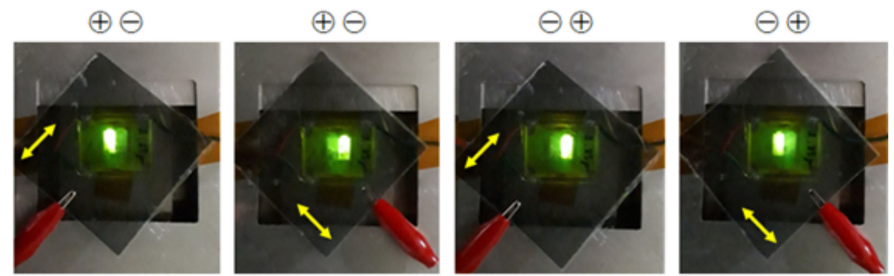

Figure 13. (a) Molecular structure of double chiral $\pi$-conjugated FLC 23. (b) Current-voltage characteristics in the chiral ordered smectic phases of compound 23. (c) Electric-field-induced rotation of the polarized plane of the electroluminescence from the polarized ordered smectic phase of compound 23. The photographs and graph were reproduced from Reference [78] with the permission from the Royal Society of Chemistry. 
The bulk photovoltaic effect in the chiral ordered smectic phase of compound 20 was enhanced by doping of fullerene derivative 24 . With the concentration of $13 \mathrm{~mol} \%$ of compound $\mathbf{2 4}$ in compound 20, fullerene-rich domains were formed in the chiral ordered phase. The photovoltaic effect was not so remarkably enhanced because the domain size was much larger than the exciton diffusion length. However, the spectral sensitivity was extended to the visible light area. The polarity of the effect could be inverted by the change of the poling bias during the cooling process from the $\mathrm{SmC}^{*}$ phase to the ordered smectic phase, as shown in Figure 14a.

(a)
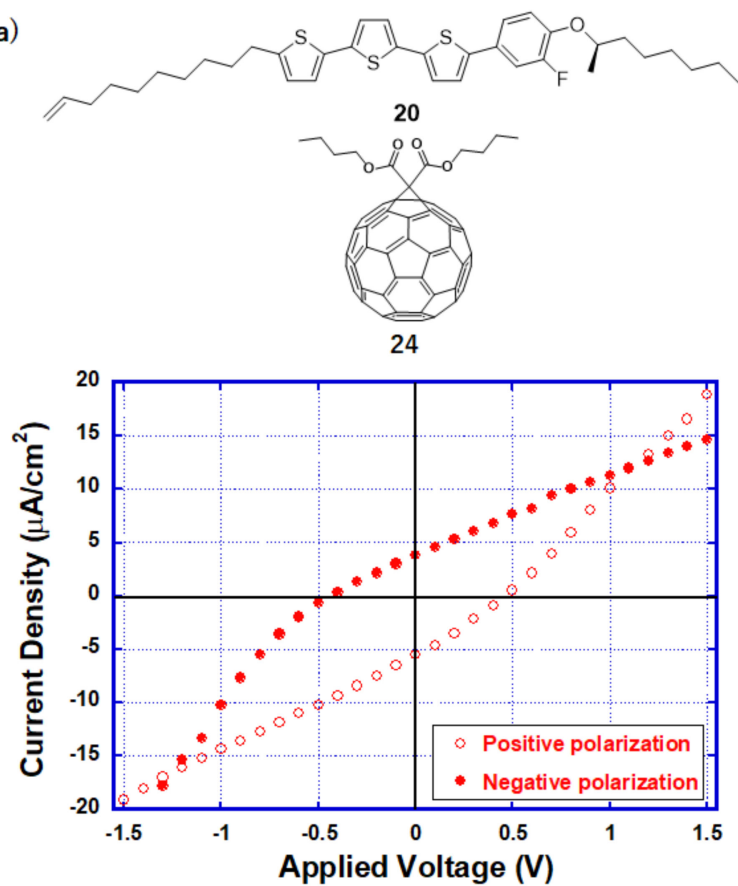

(b)
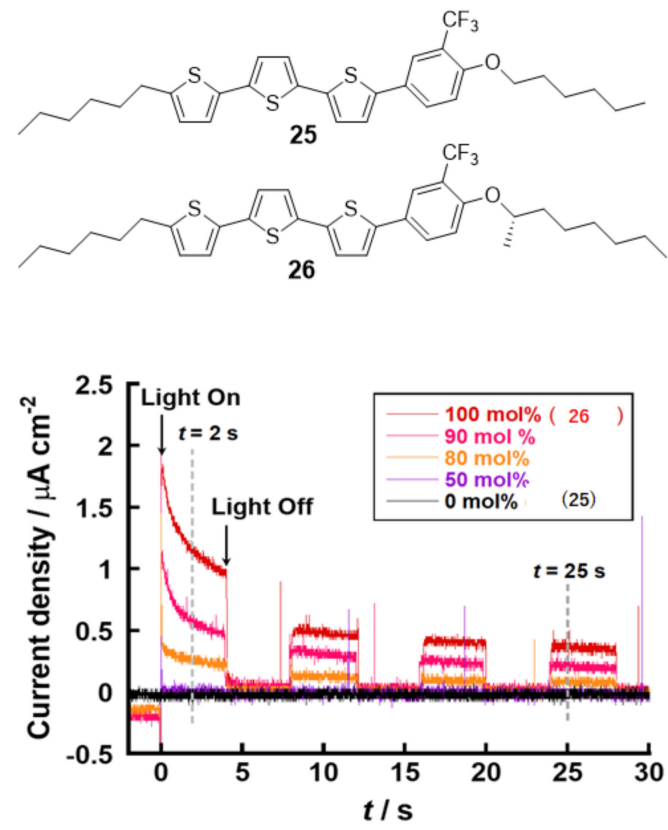

Figure 14. (a) Current-voltage characteristic in the polarized chiral ordered smectic phase of compound 20 doped with fullerene derivative 24 (13 mol \%) for white light illumination. The graph was reproduced from Reference [79] from the permission of Elsevier. (b) Photocurrent response in the $\mathrm{SmC}^{*}$ phase of the mixtures of compounds 25 and 26 under a short circuit condition. The graph was reproduced from Reference [80] from the permission from the American Chemical Society.

This bulk photovoltaic effect was also observed in binary systems consisting of a chiral and achiral FLCs [79]. The chirality induced by a small amount of chiral dopant can break the centrosymmetry of the LC electronic system, resulting in the photovoltaic effect in the ferroelectric LC phase [80]. As shown in Figure 14b, the photovoltaic effect was induced by doping of chiral compound 26 to achiral LC 25.

\subsubsection{Achiral LC Systems}

A few ferroelectric columnar LCs comprising extended $\pi$-conjugated units have been synthesized. In the studies, polar moieties and extended $\pi$-conjugated cores are integrated artfully in one-dimensional columnar structures.

Akutagawa and coworkers reported ferroelectric columnar LC 27 consisting of pyrene units and amide moieties to form one-dimensional hydrogen bonding network (Figure 15a) [81]. The electronic charge carrier transport proceeded through $\pi$-stacks consisting of pyrene cores while the hydrogen bonding networks between amide moieties induced ferroelectricity. They confirmed a shift of the current-voltage characteristics by the polarity inversion of a DC poling bias, as shown in Figure 15a, although no photovoltaic effect was observed in the ferroelectric phase. 
(a)

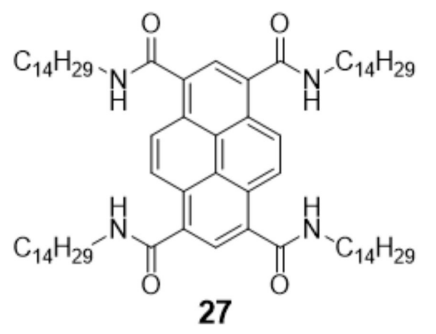

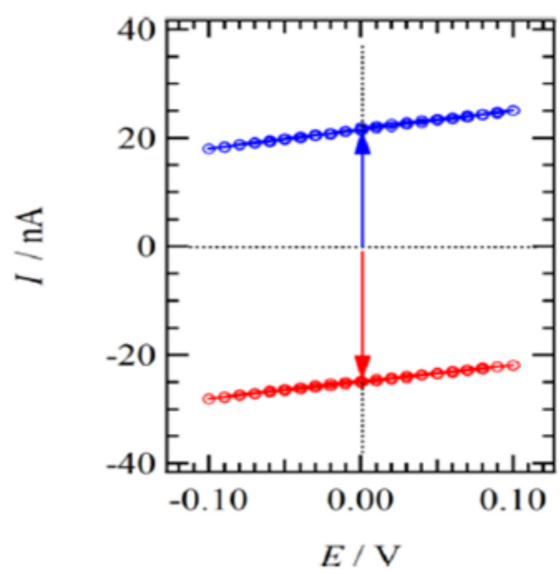

(b)
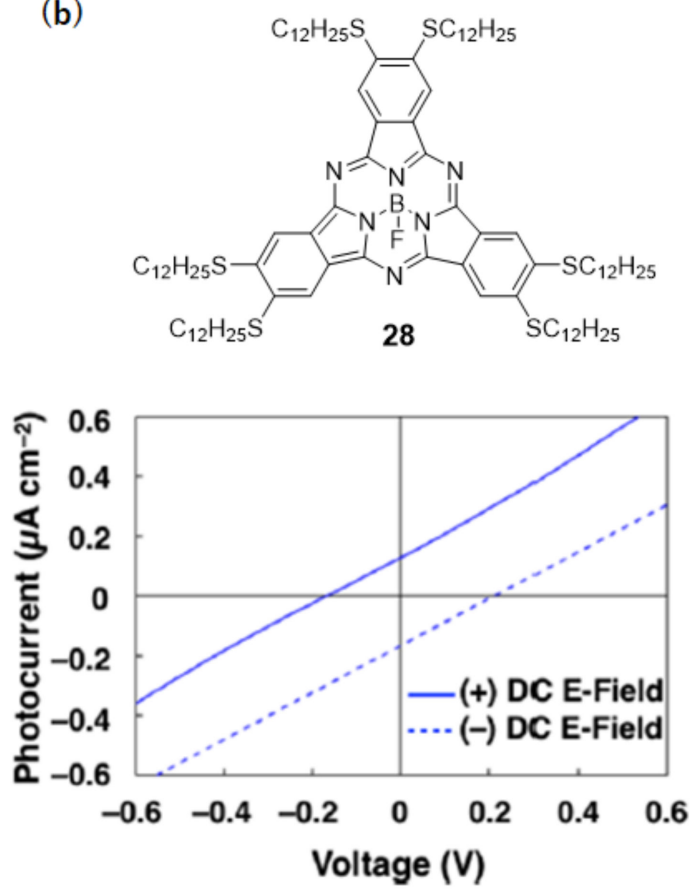

Figure 15. (a) Columnar FLC 27 based on a pyrene moiety and the current-voltage characteristic in the ferroelectric columnar phase. The graph was reproduced from Reference [81] with the permission of the American Chemical Society. (b) Ferroelectric subphthalocyanine derivative $\mathbf{2 8}$ and the current voltage characteristic in the polarized columnar phase of compound $\mathbf{2 8}$ for visible light illumination. The graph was reproduced from Reference [82] with the permission of the American Chemical Society.

Miyajima and coworkers synthesized subphthalocyanine derivative 28 exhibiting a ferroelectric columnar phase (Figure 15b) [82]. This subphthalocyanine core including boron atom was non-planar and stacked to form polarized columnar aggregates. For visible light illumination, photoconductive behavior was observed in the polarized columnar phase. The polarity of the photocurrent could be inverted by the change of the polling bias polarity and the open-circuit voltage depended on the sample thickness, as shown in Figure 15b, indicating that this photoconductivity should be attributed to a bulk photovoltaic effect.

\section{Conclusions}

Chiral liquid crystals based on extended $\pi$-conjugated units form the $\mathrm{N}^{*}$ and $\mathrm{SmC}^{*}$ phases, in which electronic function originated from the $\pi$-conjugated moieties couples with the molecular chirality to produce new optical and electronic functions. In the $\mathrm{N}^{*}$ phase, which has twisted structures, CP PL has been observed within the wavelength range of the reflection band. Recently, CP EL has been confirmed from devices based on active layers consisting of chiral conjugated polymers with twisted structures induced by the molecular chirality. FLCs, consisting of phenylterthiophene skeleton and chiral alkyl side chains, indicate a bulk photovoltaic effect, which is driven by spontaneous polarization. The bulk photovoltaic effect is enhanced in the chiral ordered smectic phases and by the formation of bulk heterojunctions with fullerene derivatives. This bulk photovoltaic effect has also been observed in achiral ferroelectric columnar LCs, which has extended $\pi$-conjugated units. 
Funding: This study was financially supported by a Grant-in-Aid for Scientific Research on Innovative Areas (Element-Block Polymers, no. 15H00753) from the Ministry of Education, Culture, Sports, Science and Technology (MEXT), a Grant-in-Aid for Scientific Research (B) (no.15H03797, 21H01904) from the Japan Society for the Promotion of Science (JSPS), the Ogasawara Foundation for the Promotion of Science \& Engineering, the SEI Group CSR Foundation, the Asahi Glass Foundation, the Salt Science Research Foundation (no. 1715), Iketani Science and Technology Foundation, and the TEPCO Memorial Foundation. This research was also supported by 'Nanotechnology Platform Program' of the Ministry of Education, Culture, Sports, Science and Technology (MEXT), Japan (Grant No. JPMXP09F19GA0004).

Institutional Review Board Statement: Not applicable.

Informed Consent Statement: Not applicable.

Data Availability Statement: Not applicable.

Acknowledgments: The author thanks Akinari Sonoda (AIST, Shikoku) for NMR measurements, Kusunose (Kagawa Univ.) for DSC measurements, and Tomohiko Ishii (Kagawa Univ.) for X-ray diffraction analysis.

Conflicts of Interest: The author declares no conflict of interest.

\section{References}

1. De Gennes, G.P.; Prost, J. The Physics of Liquid Crystals, 2nd ed.; Clarendon Press: Oxford, UK, 1997.

2. Lagerwall, S.T. Ferroelectric and Antiferroelectric Liquid Crystals; Wiley-VCH: Weinheim, Germany, 1999.

3. Kikuchi, H. Liquid Crystalline Blue Phases. Struct. Bond. 2007, 128, 99-117.

4. Renn, S.R.; Lubensky, T.C. Abrikosov dislocation lattice in a model of the cholesteric-to-smectic-A transition. Phys. Rev. A 1988, 38, 2132-2147. [CrossRef]

5. Funahashi, M. Development of Liquid-Crystalline Semiconductors with High Carrier Mobilities and Their Application to Thin-film Transistors. Polym. J. 2009, 41, 459-469. [CrossRef]

6. Funahashi, M. Nanostructured liquid-crystalline semiconductors-A new approach to soft matter electronics. J. Mater. Chem. C 2014, 2, 7451-7459. [CrossRef]

7. Funahashi, M. Solution-processable electronic and redox-active liquid crystals based on the design of side chains. Flex. Print. Electron. 2020, 5, 043001. [CrossRef]

8. O'Neill, M.; Kelly, S.M. Ordered Materials for Organic Electronics and Photonics. Adv. Mater. 2010, 23, 566-584. [CrossRef]

9. Funahashi, M.; Sonoda, A. Electron transport characteristics in nano-segregated columnar phases of perylene tetracarboxylic bisimide derivatives bearing oligosiloxane chains. Phys. Chem. Chem. Phys. 2014, 16, 7754-7763. [CrossRef] [PubMed]

10. Funahashi, M.; Ishii, T.; Sonoda, A. Temperature-Independent Hole Mobility of a Smectic Liquid-Crystalline Semiconductor based on Band-Like Conduction. ChemPhysChem 2013, 14, 2750-2758. [CrossRef]

11. Kato, T.; Yoshio, M.; Ichikawa, T.; Soberats, B.; Ohno, H.; Funahashi, M. Transport of ions and electrons in nanostructured liquid crystals. Nat. Rev. Mater. 2017, 2, 17001. [CrossRef]

12. Adam, D.; Closs, F.; Frey, T.; Funhoff, D.; Haarer, D.; Ringsdorf, H.; Schuhmacher, P.; Siemensmeyer, K. Transient photoconductivity in a discotic liquid crystal. Phys. Rev. Lett. 1993, 70, 457-460. [CrossRef]

13. van de Craats, A.M.; Warman, J.M.; Fechtenkotter, A.; Brand, J.B.; Harbison, M.A.; Mullen, K. Record Charge Carrier Mobility in a Room-Temperature Discotic Liquid-Crystalline Derivative of Hexabenzocoronene. Adv. Mater. 1999, 11, 1469-1472. [CrossRef]

14. Ban, K.; Nishikawa, K.; Ohta, K.; van de Craats, A.M.; Warman, J.M.; Yamamoto, I.; Shirai, H. Discotic liquid crystals of transition metal complexes 29: Mesomorphism and charge transport properties of alkylthiosubstituted phthalocyanine ra-re-earth metal sandwich complexes. J. Mater. Chem. 2001, 11, 321-331. [CrossRef]

15. Würthner, F.; Saha-Möller, C.R.; Fimmel, B.; Ogi, S.; Leowanawat, P.; Schmidt, D. Perylene Bisimide Dye Assemblies as Archetype Functional Supramolecular Materials. Chem. Rev. 2016, 116, 962-1052. [CrossRef] [PubMed]

16. Funahashi, M.; Sonoda, A. High electron mobility in a columnar phase of liquid-crystalline perylene tetracarboxylic bisimide bearing oligosiloxane chains. J. Mater. Chem. 2012, 22, 25190-25197. [CrossRef]

17. Funahashi, M.; Hanna, J.-I. Fast ambipolar carrier transport in smectic phases of phenylnaphthalene liquid crystal. Appl. Phys. Lett. 1997, 71, 602-604. [CrossRef]

18. Funahashi, M.; Hanna, J.-I. High Carrier Mobility up to $0.1 \mathrm{~cm}^{2} \mathrm{~V}^{-1} \mathrm{~s}^{-1}$ at Ambient Temperatures in Thiophene-Based Smectic Liquid Crystals. Adv. Mater. 2005, 17, 594-598. [CrossRef]

19. Funahashi, M.; Kato, T. Design of Liquid Crystals: From George Gray's Nematic Molecules to Thiophene-based $\pi$-Conjugated Molecules. Liq. Cryst. 2015, 42, 909-917.

20. Zhang, H.; Shiino, S.; Shishido, A.; Kanazawa, A.; Tsutsumi, O.; Shiono, T.; Ikeda, T. A Thiophene Liquid Crystal as a Novel $\pi$-Conjugated Dye for Photo-Manipulation of Molecular Alignment. Adv. Mater. 2000, 12, 1336-1339. [CrossRef] 
21. Matsui, A.; Funahashi, M.; Tsuji, T.; Kato, T. Hole Transport in Liquid-Crystalline Polymers with a Polysiloxane Backbone and a Phenylterthiophene Moiety in the Side Chain. Chem. Eur. J. 2010, 16, 13465-13472. [CrossRef]

22. Aldred, M.P.; Contoret, A.E.A.; Farrar, S.R.; Kelly, S.M.; Mathieson, D.; O'Neill, M.; Tsoi, W.C.; Vlachos, P. A Full-Color Electroluminescent Device and Patterned Photoalignment Using Light-Emitting Liquid Crystals. Adv. Mater. 2005, 17, 1368-1372. [CrossRef]

23. Funahashi, M.; Zhang, F.; Tamaoki, N. High ambipolar mobility in highly ordered smectic phase of dialkylphenylter-thiophene derivative that can be applied to solution-processed organic field effect transistors. Adv. Mater. 2007, 19, 353-358. [CrossRef]

24. Pisula, W.; Menon, A.; Stepputat, M.; Lieberwirth, I.; Kolb, U.; Tracz, A.; Sirringhaus, H.; Pakula, T.; Mullen, K. A Zone Cast-ing Technique for Device Fabrication of Field-Effect Transistors Based on Discotic Hexa-peri-Hexabenzocoronene. Adv. Mater. 2005, 17, 684-689. [CrossRef]

25. Van Breemen, A.J.J.M.; Herwig, P.T.; Chlon, C.H.T.; Sweelssen, J.; Schoo, H.F.M.; Setayesh, S.S.; Hardeman, W.M.; Martin, C.A.; De Leeuw, D.M.; Valeton, J.J.P.; et al. Large Area Liquid Crystal Monodomain Field-Effect Transistors. J. Am. Chem. Soc. 2006, 128, 2336-2345. [CrossRef]

26. Zhang, F.; Funahashi, M.; Tamaoki, N. High-performance thin film transistors from semiconducting liquid crystalline phases by solution processes. Appl. Phys. Lett. 2007, 91, 063515. [CrossRef]

27. Iino, H.; Usui, T.; Hanna, J.-I. Liquid crystals for organic thin-film transistors. Nat. Commun. 2015, 6, 6828. [CrossRef]

28. Hori, T.; Miyake, Y.; Yamasaki, N.; Yoshida, H.; Fujii, A.; Shimizu, Y.; Ozaki, M. Solution Processable Organic Solar Cell Based on Bulk Heterojunction Utilizing Phthalocyanine Derivative. Appl. Phys. Express 2010, 3, 101602. [CrossRef]

29. Shin, W.; Yasuda, T.; Watanabe, G.; Yang, Y.S.; Adachi, C. SelfOrganizing Mesomorphic Diketopyrrolo-pyrrole Deriva-tives for Efficient Solution-Processed Organic Solar Cells. Chem. Mater. 2013, 25, 2549. [CrossRef]

30. Schmidt-Mende, L.; Fechtenkötter, A.; Müllen, K.; Moons, E.; Friend, R.H.; MacKenzie, J.D. Self-Organized Discotic Liquid Crystals for High-Efficiency Organic Photovoltaics. Science 2001, 293, 1119-1122. [CrossRef]

31. Funahashi, M.; Tamaoki, N. Electronic Conduction in the Chiral Nematic Phase of an Oligothiophene Derivative. ChemPhysChem 2006, 7, 1193-1197. [CrossRef] [PubMed]

32. Funahashi, M.; Tamaoki, N. Effect of pretransitional organization in cholesteric phases of oligothiophene derivatives on their carrier transport characteristics. Chem. Mater. 2007, 19, 608-617. [CrossRef]

33. Woon, K.L.; Aldred, M.P.; Vlachos, P.; Mehl, G.H.; Stirner, T.; Kelly, S.M.; O'Neill, M. Electronic Charge Transport in Ex-tended Nematic Liquid Crystals. Chem. Mater. 2006, 18, 2311-2317. [CrossRef]

34. Tokunaga, K.; Takayashiki, Y.; Iino, H.; Hanna, J.-I. Electronic conduction in nematic phase of small molecules. Phys. Rev. B 2009, 79, 033201. [CrossRef]

35. Furumi, S.; Tamaoki, N. Glass-Forming Cholesteric Liquid Crystal Oligomers for New Tunable Solid-State Laser. Adv. Mater. 2010, 22, 886-891. [CrossRef]

36. Araoka, F.; Shin, K.-C.; Takanishi, Y.; Ishikawa, K.; Takezoe, H.; Zhu, Z.; Swager, T.M. How doping a cholesteric liquid crystal with polymeric dye improves an order parameter and makes possible low threshold lasing. J. Appl. Phys. 2003, 94, $279-283$. [CrossRef]

37. Matsui, T.; Ozaki, R.; Funamoto, K.; Ozaki, M.; Yoshino, K. Flexible mirror-less laser based on a free-standing film of photopolymerized cholesteric liquid crystal. Appl. Phys. Lett. 2002, 81, 3741-3743. [CrossRef]

38. Finkelmann, H.; Kim, S.T.; Munoz, A.; Palffy-Muhoray, P.; Taheri, B. Tunable mirrorless lasing in cholesteric liquid crystal-line elastomers. Adv. Mater. 2001, 13, 1069-1072. [CrossRef]

39. Chen, S.H.; Katsis, D.; Schmid, A.W.; Mastrangelo, J.C.; Tsutsui, T.; Blanton, T.N. Circularly polarized light generated by photoexcitation of luminophores in glassy liquid-crystal films. Nat. Cell Biol. 1999, 397, 506-508. [CrossRef]

40. Zhao, D.; He, H.; Gu, X.; Guo, L.; Wong, K.S.; Lam, J.W.Y.; Tang, B.Z. Circularly Polarized Luminescence and a Reflec-tivePhotoluminescent Chiral Nematic Liquid Crystal Display Based on an Aggregation-Induced Emission Luminogen. Adv. Opt. Mater. 2016, 4, 534-539. [CrossRef]

41. Woon, K.L.; O’Neill, M.; Richards, G.J.; Aldred, M.P.; Kelly, S.M.; Fox, A.M. Highly circularly polarized photolumines-cence over a broad spectral range from a calamitic, hole-transporting, and chiral nematic glass and from an indirectly ex-cited dye. Adv. Mater. 2003, 15, 1555-1558. [CrossRef]

42. Hamamoto, T.; Funahashi, M. Circularly polarized light emission from a chiral nematic phenylterthiophene dimer exhib-iting ambipolar carrier transport. J. Mater. Chem. C 2015, 3, 6891-6900. [CrossRef]

43. Zhang, D.-W.; Li, M.; Chen, C.-F. Recent advances in circularly polarized electroluminescence based on organic light-emitting diodes. Chem. Soc. Rev. 2020, 49, 1331-1343. [CrossRef] [PubMed]

44. Zinna, F.; Giovanella, U.; Di Bari, L. Highly Circularly Polarized Electroluminescence from a Chiral Europium Complex. Adv. Mater. 2015, 27, 1791-1795. [CrossRef]

45. Brandt, J.R.; Wang, X.-H.; Yang, Y.; Campbell, A.J.; Fuchter, M.J. Circularly Polarized Phosphorescent Electroluminescence with a High Dissymmetry Factor from PHOLEDs Based on a Platinahelicene. J. Am. Chem. Soc. 2016, 138, 9743-9746. [CrossRef] [PubMed]

46. Feuillastre, S.; Pauton, M.; Gao, L.; Desmarchelier, A.; Riives, A.J.; Prim, D.; Tondelier, D.; Geffroy, B.; Muller, G.; Clavier, G.; et al. Design and Synthesis of New Circularly Polarized Thermally Activated Delayed Fluorescence Emitters. J. Am. Chem. Soc. 2016, 138, 3990-3993. [CrossRef] [PubMed] 
47. Peeters, E.; Christiaans, M.P.T.; Janssen, R.A.J.; Schoo, H.F.M.; Dekkers, A.H.P.J.M.; Meijer, E.W. Circularly Polarized Electroluminescence from a Polymer Light-Emitting Diode. J. Am. Chem. Soc. 1997, 119, 9909-9910. [CrossRef]

48. Geng, Y.; Trajkovska, A.; Culligan, S.W.; Ou, J.J.; Chen, H.M.P.; Katsis, D.; Chen, S.H. Origin of Strong Chiroptical Activi-ties in Films of Nonafluorenes with a Varying Extent of Pendant Chirality. J. Am. Chem. Soc. 2003, 125, 14032-14038. [CrossRef]

49. Di Nuzzo, D.; Kulkarni, C.; Zhao, B.; Smolinsky, E.; Tassinari, F.; Meskers, S.C.J.; Naaman, R.; Meijer, E.W.; Friend, R.H. High Circular Polarization of Electroluminescence Achieved via Self-Assembly of a Light-Emitting Chiral Conjugated Polymer into Multidomain Cholesteric Films. ACS Nano 2017, 11, 12713-12722. [CrossRef]

50. Wan, L.; Wade, J.; Salerno, F.; Arteaga, O.; Laidlaw, B.; Wang, X.; Penfold, T.; Fuchter, M.J.; Campbell, A.J. Inverting the Handedness of Circularly Polarized Luminescence from Light-Emitting Polymers Using Film Thickness. ACS Nano 2019, 13 , 8099-8105. [CrossRef]

51. Lee, D.-M.; Song, J.-W.; Lee, Y.-J.; Yu, C.-J.; Kim, J.-H. Control of Circularly Polarized Electroluminescence in Induced Twist Structure of Conjugate Polymer. Adv. Mater. 2017, 29, 1700907. [CrossRef]

52. Jung, J.-H.; Lee, D.-M.; Kim, J.-H.; Yu, C.-J. Circularly polarized electroluminescence by controlling the emission zone in a twisted mesogenic conjugate polymer. J. Mater. Chem. C 2017, 6, 726-730. [CrossRef]

53. Butler, K.T.; Frost, J.M.; Walsh, A. Ferroelectric materials for solar energy conversion: Photoferroics revisited. Energy Environ. Sci. 2015, 8, 838-848. [CrossRef]

54. Köhler, A.; Bässler, H. Electronic Processes in Organic Semiconductors: An Introduction; Wiley-VCH Verlag GmbH \& Co. KGaA: Weinheim, Germany, 2015.

55. Elumalai, N.K.; Uddin, A. Open circuit voltage of organic solar cells: An in-depth review. Energy Environ. Sci. 2016, 9, 391-410. [CrossRef]

56. Werner, J.; Weng, C.-H.; Walter, A.; Fesquet, L.; Seif, J.P.; De Wolf, S.; Niesen, B.; Ballif, C. Efficient Monolithic Perov-skite/Silicon Tandem Solar Cell with Cell Area $>1 \mathrm{~cm}^{2}$. J. Phys. Chem. Lett. 2016, 7, 161-166. [CrossRef] [PubMed]

57. Liu, W.; Li, S.; Huang, J.; Yang, S.; Chen, J.; Zuo, L.; Shi, M.; Zhan, X.; Li, C.-Z.; Chen, H. Nonfullerene Tandem Organic Solar Cells with High Open-Circuit Voltage of 1.97 V. Adv. Mater. 2016, 28, 9729-9734. [CrossRef] [PubMed]

58. Glass, A.M.; Von Der Linde, D.; Negran, T.J. High-voltage bulk photovoltaic effect and the photorefractive process in $\mathrm{LiNbO}_{3}$ Appl. Phys. Lett. 1974, 25, 233-235. [CrossRef]

59. Koch, W.; Munser, R.; Ruppel, W.; Würfel, P. Bulk photovoltaic effect in $\mathrm{BaTiO}_{3}$. Solid State Commun. 1975, 17, 847-850. [CrossRef]

60. Choi, T.; Lee, S.; Choi, Y.J.; Kiryukhin, V.; Cheong, S.-W. Switchable Ferroelectric Diode and Photovoltaic Effect in BiFeO 3 . Science 2009, 324, 63-66. [CrossRef]

61. Yang, S.Y.; Seidel, J.; Byrnes, S.J.; Shafer, P.; Yang, C.-H.; Rossell, M.D.; Yu, P.; Chu, Y.-H.; Scott, J.F.; Ager, J.W.; et al. Above-bandgap voltages from ferroelectric photovoltaic devices. Nat. Nanotechnol. 2010, 5, 143-147. [CrossRef]

62. Horiuchi, S.; Tokura, Y. Organic ferroelectrics. Nat. Mater. 2008, 7, 357-366. [CrossRef]

63. Horiuchi, S.; Tokunaga, Y.; Giovannetti, G.; Picozzi, S.; Itoh, H.; Shimano, R.; Kumai, R.; Tokura, Y. Above-room-temperature ferroelectricity in a single-component molecular crystal. Nat. Cell Biol. 2010, 463, 789-792. [CrossRef]

64. Furukawa, T.; Nakajima, T.; Takahashi, Y. Factors governing ferroelectric switching characteristics of thin VDF/TrFE co-polymer films. IEEE Trans. Dielectric. Electr. Insul. 2006, 13, 1120-1131. [CrossRef]

65. Hartmann, W.J. Ferroelectric liquid crystal displays for television application. Ferroelectrics 1991, 122, 1-26. [CrossRef]

66. Sasabe, H.; Nakayama, T.; Kumazawa, K.; Miyata, S.; Fukada, E. Photovoltaic Effect in Poly(vinilydene fluoride). Polym. J. 1981, 13, 967-973. [CrossRef]

67. Sugita, A.; Suzuki, K.; Tasaka, S. Ferroelectric properties of a triphenylene derivative with polar functional groups in the crystalline state. Phys. Rev. B 2004, 69, 212201. [CrossRef]

68. Nakamura, M.; Horiuchi, S.; Kagawa, F.; Ogawa, N.; Kurumaji, T.; Tokura, Y.; Kawasaki, M. Shift current photovoltaic effect in a ferroelectric charge-transfer complex. Nat. Commun. 2017, 8, 1-6. [CrossRef]

69. Meyer, R.B.; Liebert, L.; Strzelecki, L.; Keller, P. Ferroelectric liquid crystals. J. Phys. Lett. 1975, 36, 69-71. [CrossRef]

70. Clark, N.A.; Lagerwall, S.T. Submicrosecond bistable electro-optic switching in liquid crystals. Appl. Phys. Lett. 1980, 36, 899-901. [CrossRef]

71. Bock, H.; Helfrich, W. Two ferroelectric phases of a columnar dibenzopyrene. Liq. Cryst. 1995, 18, 387-399. [CrossRef]

72. Kishikawa, K.; Nakahara, S.; Nishikawa, Y.; Kohmoto, S.; Yamamoto, M. A Ferroelectrically Switchable Columnar Liquid Crystal Phase with Achiral Molecules: Superstructures and Properties of Liquid Crystalline Ureas. J. Am. Chem. Soc. 2005, 127, $2565-2571$. [CrossRef]

73. Miyajima, D.; Araoka, F.; Takezoe, H.; Kim, J.; Kato, K.; Takata, M.; Aida, T. Ferroelectric Columnar Liquid Crystal Featur-ing Confined Polar Groups within Core-Shell Architecture. Science 2012, 336, 209-213. [CrossRef]

74. Funatsu, Y.; Sonoda, A.; Funahashi, M. Ferroelectric liquid-crystalline semiconductors based on a phenylterthiophene skel-eton: Effect of introduction of oligosiloxane moieties and photovoltaic effect. J. Mater. Chem. C 2015, 3, 1982-1993. [CrossRef]

75. Seki, A.; Funahashi, M. Photovoltaic Effects in Ferroelectric Liquid Crystals based on Phenylterthiophene Derivatives. Chem. Lett. 2016, 45, 616-618. [CrossRef]

76. Seki, A.; Funatsu, Y.; Funahashi, M.; Seki, A. Anomalous photovoltaic effect based on molecular chirality: Influence of enantiomeric purity on the photocurrent response in $\pi$-conjugated ferroelectric liquid crystals. Phys. Chem. Chem. Phys. 2017, 19, 16446-16455. [CrossRef] 
77. Seki, A.; Funahashi, M. Chiral photovoltaic effect in an ordered smectic phase of a phenylterthiophene derivative. Org. Electron. 2018, 62, 311-319. [CrossRef]

78. Funahashi, M.; Mori, Y. Linearly polarized electroluminescence device in which the polarized plane can be rotated electri-cally using a chiral liquid crystalline semiconductor. Mater. Chem. Front. 2020, 4, 2137-2148. [CrossRef]

79. Mori, Y.; Funahashi, M. Bulk photovoltaic effect in organic binary systems consisting of a ferroelectric liquid crystalline semiconductor and fullerene derivatives. Org. Electron. 2020, 87, 105962. [CrossRef]

80. Seki, A.; Yoshio, M.; Mori, Y.; Funahashi, M. Ferroelectric Liquid-Crystalline Binary Mixtures Based on Achiral and Chiral Trifluoromethylphenylterthiophenes. ACS Appl. Mater. Interfaces 2020, 12, 53029-53038. [CrossRef]

81. Anetai, H.; Wada, Y.; Takeda, T.; Hoshino, N.; Yamamoto, S.; Mitsuishi, M.; Takenobu, T.; Akutagawa, T. Fluorescent Ferro-electrics of Hydrogen-Bonded Pyrene Derivatives. J. Phys. Chem. Lett. 2015, 6, 1813-1818. [CrossRef] [PubMed]

82. Zhang, C.; Nakano, K.; Nakamura, M.; Araoka, F.; Tajima, K.; Miyajima, D. Noncentrosymmetric Columnar Liquid Crystals with the Bulk Photovoltaic Effect for Organic Photodetectors. J. Am. Chem. Soc. 2020, 142, 3326-3330. [CrossRef] 